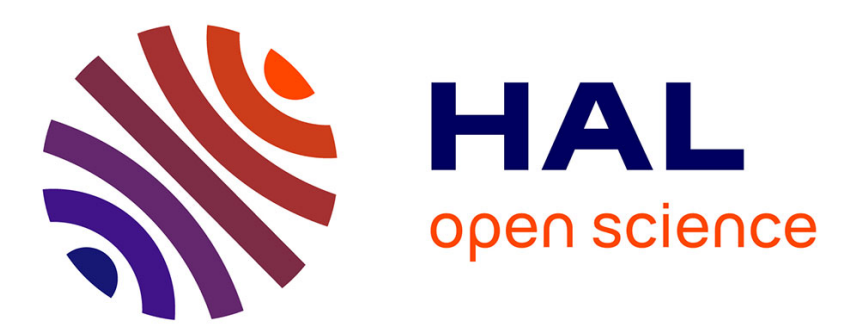

\title{
On the Predictability of the Winter Euro-Atlantic Climate: Lagged Influence of Autumn Arctic Sea Ice
}

Javier García-Serrano, Claude Frankignoul, Guillaume Gastineau, Alvaro de La Càmara

\section{- To cite this version: \\ Javier García-Serrano, Claude Frankignoul, Guillaume Gastineau, Alvaro de La Càmara. On the Predictability of the Winter Euro-Atlantic Climate: Lagged Influence of Autumn Arctic Sea Ice. Journal of Climate, 2015, 28 (13), pp.5195-5216. 10.1175/JCLI-D-14-00472.1 . hal-01191761}

\section{HAL Id: hal-01191761 \\ https://hal.sorbonne-universite.fr/hal-01191761}

Submitted on 2 Sep 2015

HAL is a multi-disciplinary open access archive for the deposit and dissemination of scientific research documents, whether they are published or not. The documents may come from teaching and research institutions in France or abroad, or from public or private research centers.
L'archive ouverte pluridisciplinaire HAL, est destinée au dépôt et à la diffusion de documents scientifiques de niveau recherche, publiés ou non, émanant des établissements d'enseignement et de recherche français ou étrangers, des laboratoires publics ou privés. 


\title{
On the Predictability of the Winter Euro-Atlantic Climate: Lagged Influence of Autumn Arctic Sea Ice
}

\author{
J. García-Serrano, C. Frankignoul, And G. Gastineau \\ LOCEAN/IPSL, Sorbonne Universités (UPMC, Université Paris 06)-CNRS-IRD-MNHN, Paris, France
}

\author{
A. DE LA CÁMARA
}

Laboratoire de Météorologie Dynamique (IPSL/CNRS), École Normale Supérieure, Paris, France

(Manuscript received 3 July 2014, in final form 19 March 2015)

\begin{abstract}
Satellite-derived sea ice concentration (SIC) and reanalyzed atmospheric data are used to explore the predictability of the winter Euro-Atlantic climate resulting from autumn SIC variability over the BarentsKara Seas region (SIC/BK). The period of study is 1979/80-2012/13. Maximum covariance analyses show that the leading predictand is indistinguishable from the North Atlantic Oscillation (NAO). The leading covariability mode between September SIC/BK and winter North Atlantic-European sea level pressure (SLP) is not significant, indicating that no empirical prediction skill can be achieved. The leading covariability mode with either October or November SIC/BK is moderately significant (significance levels $<10 \%$ ), and both predictor fields yield a cross-validated NAO correlation of 0.3 , suggesting some empirical prediction skill of the winter NAO index, with sea ice reduction in the Barents-Kara Seas being accompanied by a negative NAO phase in winter. However, only November SIC/BK provides significant cross-validated skill of winter SLP, surface air temperature, and precipitation anomalies over the Euro-Atlantic sector, namely in southwestern Europe. Statistical analysis suggests that November SIC/BK anomalies are associated with a Rossby wave train-like anomaly across Eurasia that affects vertical wave activity modulating the stratospheric vortex strength, which is then followed by downward propagation of anomalies that impact transient-eddy activity in the upper troposphere, helping to settle and maintain the NAO-like pattern at surface. This stratospheric pathway is not detected when using October SIC/BK anomalies. Hence, only November SIC/BK, with a onemonth lead time, could be considered as a potential source of regional predictability.
\end{abstract}

\section{Introduction}

The winter North Atlantic Oscillation (NAO) dominates the interannual atmospheric variability in the Euro-Atlantic sector and largely contributes to regional surface climate variability (e.g., Hurrell et al. 2003, Hurrell and Deser 2009). The NAO is frequently regarded as the regional expression of the Arctic Oscillation or northern annular mode (AO/NAM; e.g., Thompson et al. 2003). In recent years, there has been substantial progress in understanding the atmospheric processes involved in the NAO (e.g., Ambaum and Hoskins 2002; Branstator 2002; Vallis et al. 2004; Vallis

Corresponding author address: J. García-Serrano, LOCEAN/ IPSL, Université Pierre et Marie Curie (UPMC), 4 Place Jussieu, Tour 45-55 5e, Paris 75252, France.

E-mail: javier.garcia-serrano@locean-ipsl.upmc.fr and Gerber 2008; Woollings et al. 2008; Gerber and Vallis 2009; Watanabe 2009; García-Serrano et al. 2011). These studies have implied that most of the circulation variability associated with the NAO arises from internal, nonlinear dynamics of the extratropical atmosphere. Thus, the month-to-month and year-to-year changes in the phase and amplitude of the NAO appeared to be unpredictable (Hurrell and Deser 2009). However, there is increasing evidence that the low-frequency variability of the winter NAO is in part driven by surface changes, thus enhancing its potential predictability. The aim of this study is to further document the role of interannual variability in autumn Arctic sea ice concentration (SIC).

Sea ice variations have a strong impact on heat and moisture fluxes and can thus influence both local and large-scale atmospheric circulation. Sea ice forcing of the atmosphere can be as important as atmospheric forcing of the sea ice in some seasons (Walsh and Johnson 1979). 
Low-frequency Arctic sea ice variations have received more attention in recent years because of its declining trends (for review, see Bader et al. 2011; Vihma 2014; Walsh 2014). Observational and modeling studies have largely focused on evaluating the winter atmospheric response to winter sea ice anomalies (e.g., Alexander et al. 2004; Strong et al. 2009; Frankignoul et al. 2014; Liptak and Strong 2014). Early atmospheric general circulation model (AGCM) experiments showed that prescribing winter Arctic sea ice reduction trends leads to a negative NAO-like response (Magnusdottir et al. 2004), which is largely controlled by the transient-eddy feedback (Deser et al. 2004, 2007). Recent AGCM experiments, however, show contradictory results, yielding either a negative (Deser et al. 2010) or a positive (Screen et al. 2014) NAO-like circulation anomaly in response to winter Arctic sea ice trends. The atmospheric response appears to be weak (Seierstad and Bader 2009), masked by internal variability (Screen et al. 2013), and not robust across simulations (Screen et al. 2014). Petoukhov and Semenov (2010) indicate that the winter atmospheric response to a retreat in the sea ice edge over the BarentsKara Seas region is highly nonlinear to reduction. There is no consensus either on the impact of the Arctic temperature amplification on midlatitude planetary waves (Francis and Vavrus 2012; Screen and Simmonds 2013; Barnes 2013).

However, our study focuses on interannual variability rather than trends, aiming to gain insight into the influence of autumn Arctic sea ice variability on the winter Euro-Atlantic atmospheric circulation. Previous observational results show that, during recent decades, negative Arctic sea ice anomalies (corresponding to a retreat of the sea ice edge) in autumn leads to a negative NAO-like circulation anomaly in the following winter (Wu and Zhang 2010; Liu et al. 2012; Tang et al. 2013), with the Barents-Kara-Laptev Seas having the largest influence ( $\mathrm{Li}$ and Wang 2013).

How autumn Arctic sea ice anomalies influence the atmospheric circulation in autumn has been less explored. Francis et al. (2009) showed by compositing lowice minus high-ice years that a sea ice reduction in September is followed in October-November by anticyclonic anomalies over northern Eurasia and cyclonic anomalies over western Europe and central-eastern Eurasia. By means of AGCM sensitivity experiments, Honda et al. (2009) argue that the circulation anomaly over Eurasia in November can be regarded as a stationary Rossby wave train thermally triggered by sea ice variations in the Barents-Kara Seas region.

In this study, we establish the spatial pattern of the SIC anomalies over the eastern Arctic that most impact the winter Euro-Atlantic atmospheric circulation, and discuss the predictability of the winter European climate that can be achieved from this covariability (section 3a). We then explore the mechanisms that control the atmospheric anomalies associated with the SIC variability in November, which stands for the potential source of regional predictability (section $3 b$ ). Next, the atmospheric anomalies associated with the SIC variability in October are briefly discussed (section 3c). Concluding remarks are given in section 4.

\section{Datasets and methodology}

This study is based on lagged maximum covariance analysis (MCA; e.g., Bretherton et al. 1992; Czaja and Frankignoul 2002) between winter sea level pressure (SLP) anomalies, the predictand, and SIC anomalies, the predictor. The MCA estimates the main modes of covariability between two fields while making no a priori assumption on the spatial patterns. It performs a singular value decomposition of their (area weighted) covariance matrix, and provides a pair of spatial patterns and associated standardized time series (hereafter, expansion coefficients) for each covariability mode. Each mode is characterized by the squared covariance (sc), the squared covariance fraction (scf), a measure of the fraction of covariability explained, and the correlation between the expansion coefficients (cor). The statistical significance of the MCA modes is evaluated with a Monte Carlo test, based on 100 permutations shuffling only the atmospheric field (SLP) with replacement; the significance level (hereafter $p$ value) is given by the numbers of randomized values that exceed the actual values being tested. The significance of the linear relationship between the two fields is further evaluated by calculating the root-mean-square covariance (rmsc; e.g., Schneider et al. 2004), where a value greater than 0.1 is for well-correlated fields. Canonical correlation analysis (CCA; e.g., Wallace et al. 1992) is also used, since nonnormalized data may skew results. However, CCA did not produce remarkable differences with the MCA spatial patterns. Because CCA looks for modes of maximum correlation instead of maximum covariance, which could lead to an overestimation of the correlation skill for winter Euro-Atlantic climate, we only present the MCA results.

The predictand field is SLP anomalies over the North Atlantic-European region $20^{\circ}-90^{\circ} \mathrm{N}, 90^{\circ} \mathrm{W}-40^{\circ} \mathrm{E}$ averaged from December to February (DJF) as given by the ERA-Interim (hereafter ERA-Int), available from the European Centre for Medium-Range Weather Forecasts (ECMWF; Dee et al. 2011). The same region and season are used to define the winter NAO index, obtained as the leading principal component of detrended 


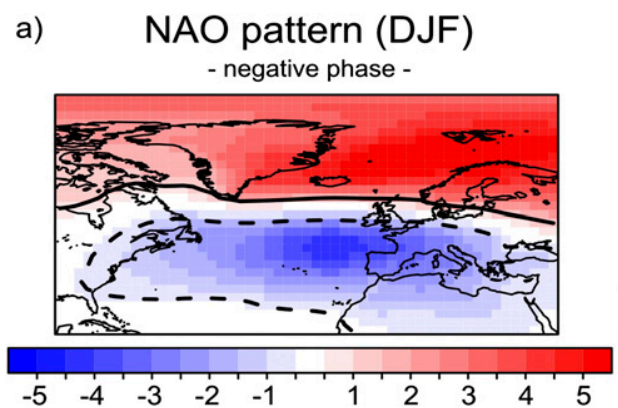

\section{b) NAO index (DJF) 1979/80-2012/13}

FIG. 1. (a) Leading EOF of detrended winter SLP anomalies over the North Atlantic-European sector. The pattern is displayed in terms of amplitude ( $\mathrm{hPa}$ ) by regressing detrended SLP anomalies onto the leading principal component [solid line in (b)]; the negative NAO phase is shown. Statistically significant areas at $95 \%$ confidence level based on a two-tailed Student's $t$ test are contoured. (b) Leading principal component of the EOF analysis using detrended (solid line) and undetrended (dashed line) SLP anomalies; the shading is the difference between both time series.

winter SLP anomalies (Fig. 1; e.g., Hurrell et al. 2003); the correlation between the detrended (Fig. 1b, solid line) and undetrended (Fig. 1b, dashed line) winter NAO index is 0.96 . The predictor fields are monthly Arctic SIC anomalies in September-November, which provide 3- to 1-month lead times. The SIC dataset is from the NOAA/NCDC passive microwave monthly Northern Hemisphere sea ice concentration record, provided by the National Snow and Ice Data Center (NSIDC; Comiso 2012). No threshold for the absence or presence of sea ice has been applied (i.e., continuous fractions have been used). We consider the 1979/80 2012/13 period.

To explore the dynamical mechanisms involved in the SIC influence, different atmospheric fields are extracted from ERA-Int. In addition to SLP, daily geopotential height from 1000 to $1 \mathrm{hPa}$ (37 vertical levels) is used. Daily zonal $(u)$ and meridional $(v)$ wind at $200 \mathrm{hPa}$ are retrieved to analyze the role of internal dynamics and eddy-mean flow interaction through the perturbation kinetic energy (PKE), where PKE $=0.5\left(u^{\prime} u^{\prime}+v^{\prime} v^{\prime}\right)$, and eddy momentum flux $\left(u^{\prime} v^{\prime}\right)$, where the time-mean covariances have been computed from filtered daily data using a 24-h difference filter (e.g., Wallace et al. 1988; Chang and $\mathrm{Fu}$ 2002). The wave activity flux at $200 \mathrm{hPa}$ is also computed as in Karoly et al. (1989); it is derived from the zonally asymmetric component (departure from zonal mean) of the geopotential height regression map and provides a diagnostic of the horizontal propagation of quasi-stationary anomalies in the troposphere. Daily meridional wind $(v)$ and air temperature $(T)$ at $100 \mathrm{hPa}$ are retrieved to diagnose the wave forcing of the stratosphere through the eddy heat flux $v^{*} T^{*}$, where the asterisks denote departures from the zonal mean; the time-mean covariance has been performed after computing the eddy component in each field and for each day of the month (e.g., Newman and Nash 2000; Hinssen and Ambaum 2010). To assess the anomalous heating of the lower troposphere through changes in the surface turbulent heat flux, 3-hourly forecastaccumulated sensible and latent heat flux initialized twice per day (0000 and 1200 UTC) are also used. All monthly anomalies are calculated by subtracting the corresponding monthly climatology. To reduce the effect of long-term trends, a third-order polynomial (i.e., cubic trend) is removed by least squares fit at each grid point for all anomalous fields before performing the multivariate or univariate analyses. We found, however, that linear detrending yields very similar results.

The empirical prediction model used in the study is based on linear regression where the predictand is either the winter NAO index or gridpoint anomalies. For the latter, SLP and surface air temperature (SAT) at $2 \mathrm{~m}$ from ERA-Int, together with the satellitederived land-ocean Global Precipitation Climatology Project (GPCP), version 2.2, dataset provided by NASA GSFC's Laboratory for Atmospheres (Adler et al. 2003), are considered. The statistical model follows a one-year-out cross-validation method, which avoids artificial skill (e.g., Coelho et al. 2004). We verified that a three-year-out cross-validation approach (e.g., Rodrigues et al. 2014) provides identical results. Crossvalidated hindcasts are produced by cross-validating the MCA pattern generation in the year out, thus performing MCA on the remaining years and using the corresponding SIC time series to estimate the regression coefficients (i.e., slope and intercept); the predictor value for the statistical model is estimated by regressing the corresponding MCA-SIC pattern on the SIC anomalies of the year out. The reader is referred to the retraction note in García-Serrano and Frankignoul (2014) for details on the skill overestimation of not following this cross-validation 
approach. Statistical significance of the cross-validated hindcasts (correlation/regression analyses) is assessed with a one-tailed (two-tailed) Student's $t$ test for correlation at $95 \%$ confidence level. To avoid obtaining too liberal statistical thresholds, we use an effective sample size that takes into account the autocorrelation of the winter NAO index, yielding 25 degrees of freedom from the 34 -yr time period of the study.

\section{Results}

The winter NAO has experienced secular changes in the longitudinal position of its centers of action; after the late 1970s, which is the period of interest in this study, the NAO pattern showed a marked northeastward shift in the northern node (e.g., Hilmer and Jung 2000; Jung et al. 2003). Figure 1a depicts the winter NAO pattern, in its negative phase, as leading EOF of detrended SLP anomalies in the North Atlantic-European sector. It explains $53 \%$ of the regional SLP variance during 1979/80-2012/13. Note that the maximum amplitude of the anomalies at subpolar latitudes is between Iceland and the Scandinavian Peninsula. Figure 1b (solid line) shows the winter NAO index, the time series associated with the leading EOF or leading principal component. It mainly exhibits interannual variations, such as the extreme negative event of 2009/10 (e.g., Jung et al. 2011).

\section{a. Covariability and predictability}

To exploit the lead time of the winter Euro-Atlantic atmospheric circulation predictability from autumn Arctic SIC anomalies, an MCA based on each autumnal month (September through November) is performed, thus refining previous studies based on seasonally averaged sea ice anomalies (Wu and Zhang 2010; Liu et al. 2012; Li and Wang 2013; Tang et al. 2013). According to previous evidence (Honda et al. 2009; Petoukhov and Semenov 2010; Wu and Zhang 2010; Li and Wang 2013), a targeted domain is used for SIC, namely the eastern Arctic, whose loadings are over the Barents-Kara Seas region (SIC/BK). Using SIC anomalies over the whole Arctic does not yield significant covariability modes for any month (not shown); accordingly, limited skill can be achieved [see retraction note in García-Serrano and Frankignoul (2014)]. By limiting the domain of study in the MCA, the noise is expected to be reduced and the significance in covariability is expected to increase. Even so, the leading mode of covariability between September SIC/BK anomalies and winter Euro-Atlantic SLP anomalies is not sufficiently statistically significant $(p$ values of $16 \%, 36 \%$, and $11 \%$ for the sc, scf, and cor, respectively); hence, it is not discussed (see appendix).
The leading MCA mode based on October SIC/BK anomalies explains $79 \%$ of the scf ( $p$ value $=4 \%$ ), with an sc value of $1.26 \times 10^{8}$ ( $p$ value $\left.=2 \%\right)$, and yields a cor of 0.56 ( $p$ value $=18 \%)$. The latter is only weakly significant, but the covariability shows good significance. This is consistent with a relatively high rmsc of 0.23 between the two fields. Figure 2 shows the SIC homogeneous regression map (Fig. 2a) and SLP heterogeneous regression map (Fig. 2b) onto the SIC expansion coefficient (MCA-SIC/BK ${ }_{\mathrm{OCT}}$ ). The SIC pattern displays negative anomalies (i.e., sea ice reduction) over the northern Barents Sea and central-northern Kara Sea, with amplitudes larger than $20 \%$. The corresponding SLP expansion coefficient correlates at -0.99 with the winter NAO index; hence, the October SIC anomalies associated with MCA-SIC/BK $\mathrm{BCT}_{\mathrm{OCT}}$ are followed by a negative NAO-like pattern in winter (Fig. 2b). The leading MCA mode based on November SIC/BK anomalies explains $75 \%$ of the $\operatorname{scf}(p$ value $=$ $8 \%)$, with an sc of $1.02 \times 10^{8}(p$ value $=3 \%)$ and a cor of $0.59(p$ value $=18 \%)$. The latter is again only weakly significant, but the covariability shows good significance as well. This is in agreement with a relatively high rmsc of 0.21 . The SIC pattern (Fig. 3a) exhibits strong negative anomalies (larger than $-20 \%$ ) over the northern Barents Sea and southern Kara Sea. Note that the SIC anomalies in October and November follow the climatological expansion of the sea ice edge (green contour in Figs. 2a and 3a). The SLP pattern (Fig. 3b) closely resembles the NAO (Fig. 1a), and the SLP expansion coefficient correlates at -0.99 with the winter NAO index; thereby, the November SIC anomalies associated with

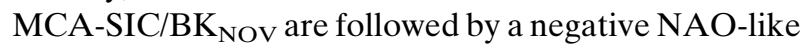
pattern in winter (Fig. 3b). To verify that the winter SLP covariability patterns (Figs. $2 \mathrm{~b}$ and $3 \mathrm{~b}$ ) are not dominated by a single month, Fig. 4 shows SLP regression maps for individual winter months. All regressions show an NAO-like pattern. However, it can be seen that MCA-SIC/BK $_{\text {NOV }}$ (Fig. 4, right) yields more consistent and significant intraseasonal patterns than MCA-SIC/ $\mathrm{BK}_{\mathrm{OCT}}$ (Fig. 4, left), especially at midlatitudes. Nonetheless, our focus is on the seasonal, winter EuroAtlantic climate.

Following the encouraging statistical significance of the covariability modes shown in Figs. 2 and 3, cross-validated hindcasts have been performed upon the winter NAO index using SIC/BK in October and November as predictor. The statistical prediction model follows a one-year-out cross-validation method, where cross-validated hindcasts are produced by cross-validating the MCA pattern generation in the year out (see section 2). The cross-validated NAO skill based on October SIC/BK is 0.31 , and 


\section{a) MCA-SIC/BKoct}

\section{$\mathrm{sc}=1.26 \mathrm{scf}=79.4 \%$ cor $=0.56$}
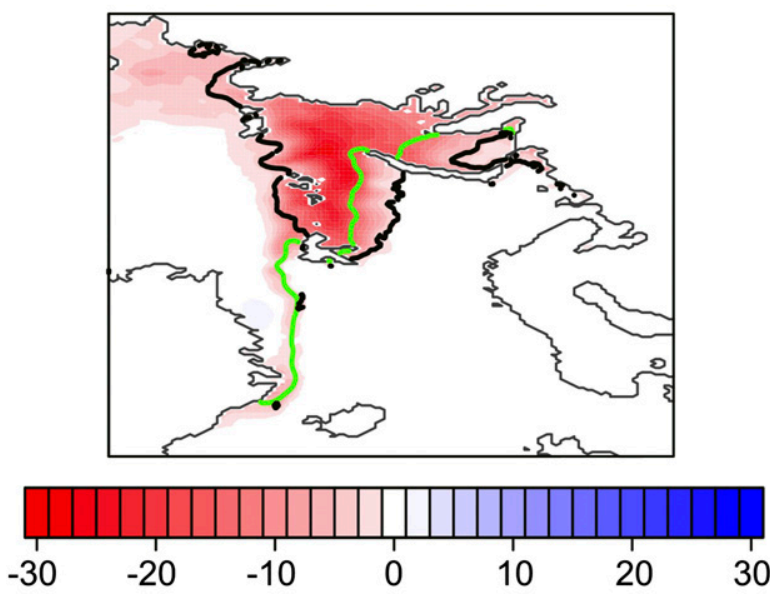

b) MCA-SIC/BKост $\times$ SLP (DJF)
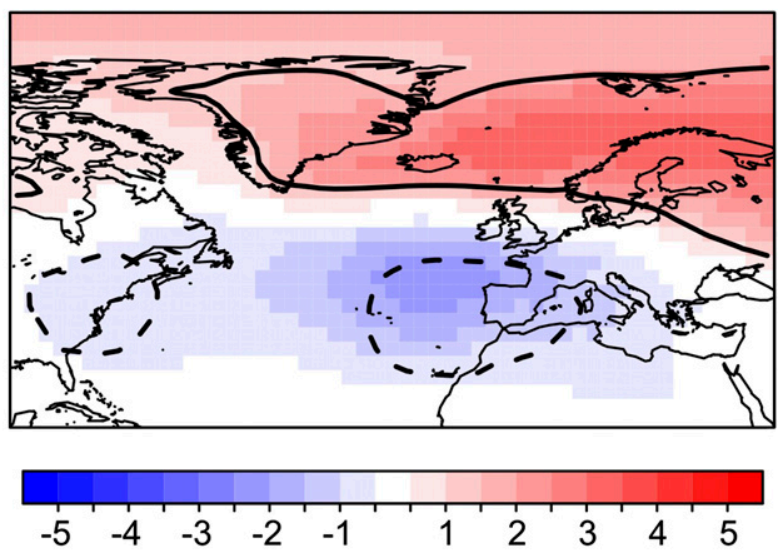
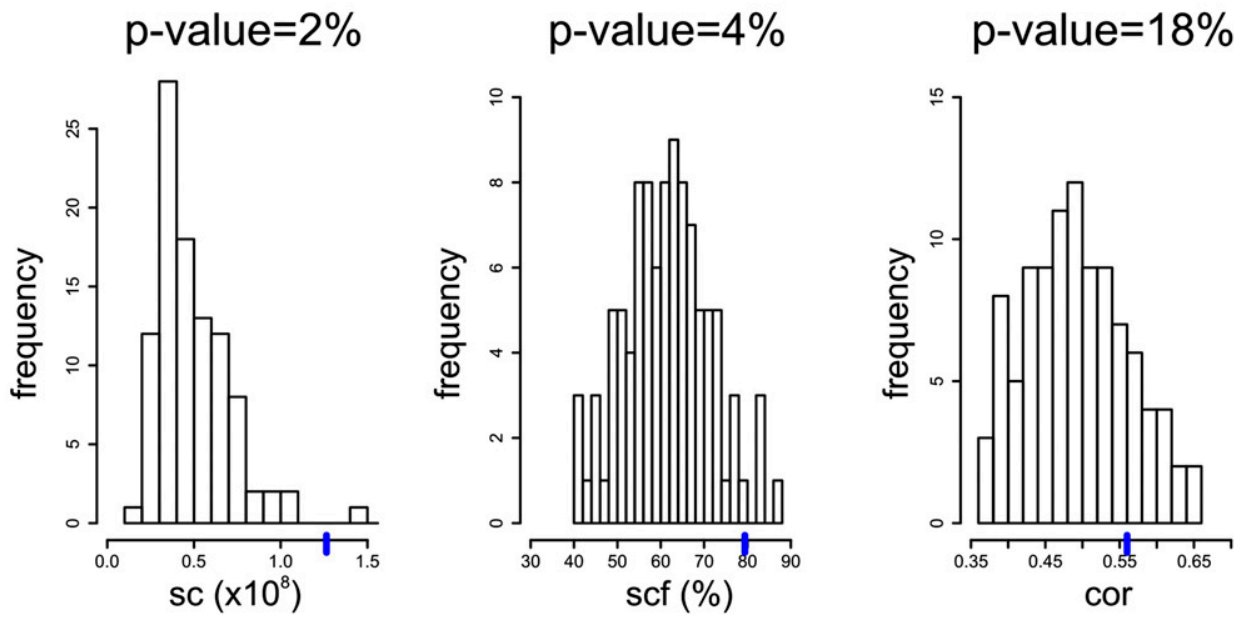

FIG. 2. Leading MCA covariability mode between (a) detrended October SIC anomalies over the eastern Arctic (\%; predictor field) and (b) winter SLP anomalies over the North Atlantic-European sector ( $\mathrm{hPa}$; predictand field); the squared covariance (sc; $\left.10^{8}\right)$, the squared covariance fraction (scf; \%) explained by the MCA mode, and the correlation between expansion coefficients (cor) are indicated. Shown in (a),(b) are regression maps of detrended anomalies onto the MCA-SIC/BK expansion coefficient. Statistically significant areas at $95 \%$ confidence level based on a two-tailed Student's $t$ test are contoured. The monthly climatology of SIC is denoted by a green line in (a), estimated by the $25 \%$ fraction. (bottom) Monte Carlo test for statistical significance applied to (left) sc, (center) scf, and (right) cor, based on 100 permutations shuffling only the atmospheric field (SLP) with replacement.

the one based on November SIC/BK is 0.29 . These correlation scores are not statistically significant at $95 \%$ confidence level, but suggest some prediction skill of the winter NAO from Arctic sea ice variability over the Barents-Kara Seas in middle-to-late autumn.

To illustrate the actual predictability of the winter Euro-Atlantic surface climate from autumn SIC/BK variability, cross-validated hindcasts have been performed upon gridpoint ERA-Int SLP and SAT and GPCP precipitation anomalies using SIC/BK in October and November as predictor. Although the target here is the regional predictability, the skill maps are displayed covering most of Eurasia to explore the link with its recent severe winters (e.g., Cohen et al. 2014; Mori et al. 2014). However, the reader is reminded that this study focuses on variability and predictability around the trends. The cross-validated skill pattern of winter SLP based on October (Fig. 5a) and November (Fig. 5b) SIC/BK is reminiscent of the NAO-like pattern in Figs. $2 b$ and $3 \mathrm{~b}$, but only the one using November SIC/BK as predictor achieves statistically significant scores in the Euro-Atlantic region (Fig. 5b). The contribution of February to the November SIC/BK skill of winter SLP might be restricted to North Atlantic midlatitudes 
a) MCA-SIC/BKNov $\mathrm{sc}=1.02 \mathrm{scf}=74.9 \%$ cor $=0.59$
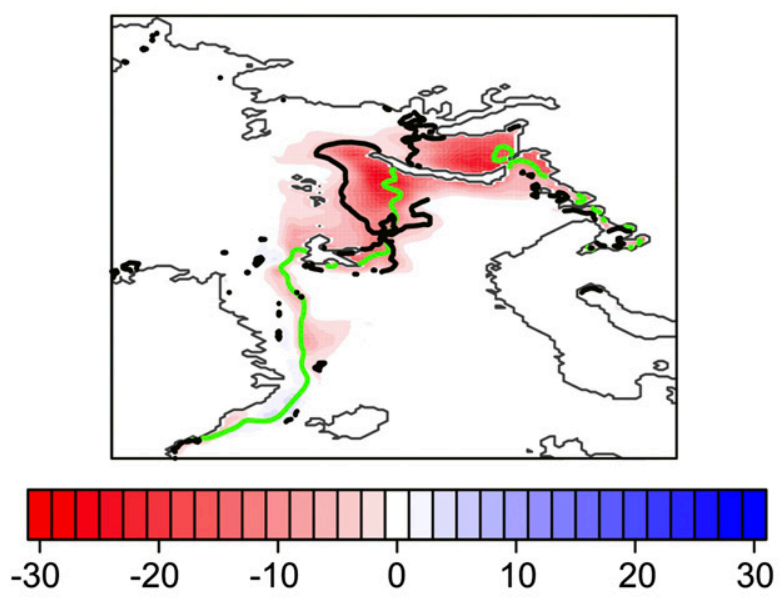

b) MCA-SIC/BK Nov $\times$ SLP $(D J F)$
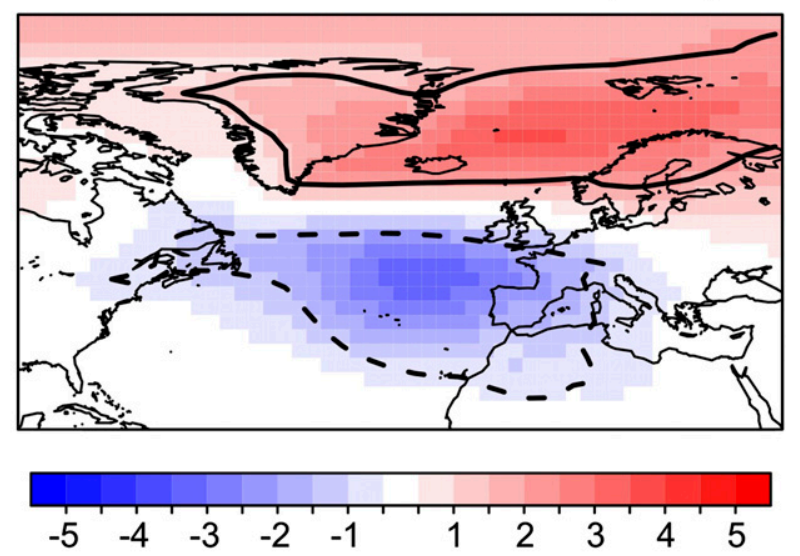

\section{p-value $=3 \%$}

$p$-value $=8 \%$

\section{$p$-value $=18 \%$}
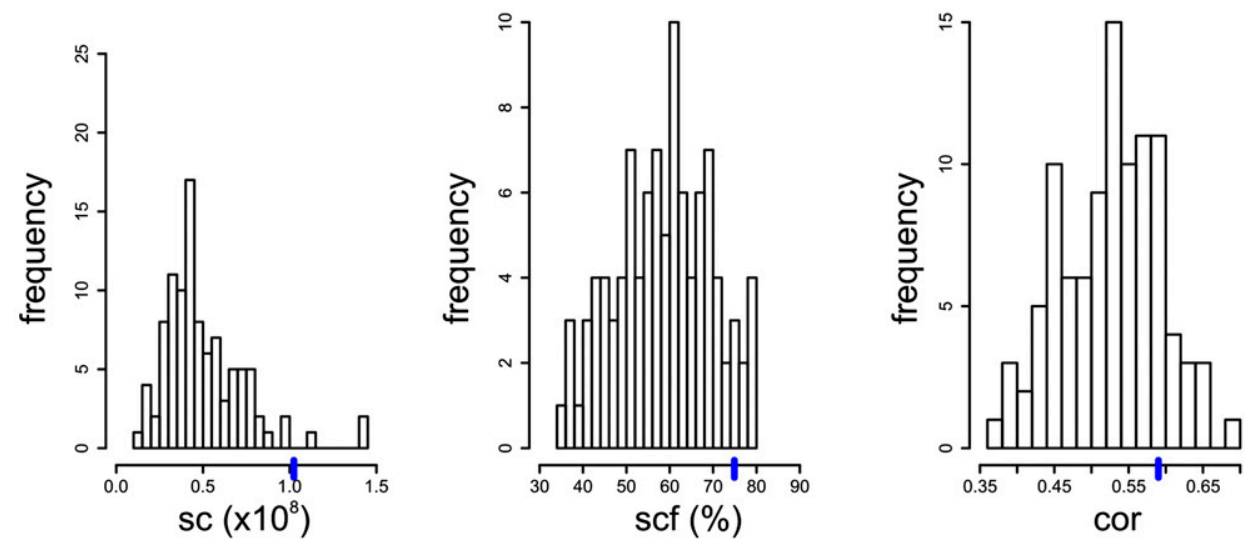

FIG. 3. As in Fig. 2, but for November SIC anomalies.

according to its limited significance (Fig. 4f) as compared to December-January (Figs. 4b,d). The crossvalidated skill patterns of winter SAT and precipitation, although showing positive scores over Europe, do not achieve $95 \%$ confidence level using October SIC/BK (Figs. 5c,e) and only some regions exceed the statistical threshold using November SIC/BK (Figs. 5d,f). Note that although there are large areas of significant linear correlation with the MCA-SIC/BK $\mathrm{BOV}_{\mathrm{NO}}$ expansion coefficient (thin colored line), the prediction skill is limited (thick black line). Nonetheless, this statistically significant skill of SAT over the central-western Mediterranean basin and of precipitation over the Iberian Peninsula represents the first hint that statistical predictions of winter European climate based on sea ice variability over the Barents-Kara Seas in middle-to-late autumn could be skillful. These results from empirical hindcasts support the recent finding from dynamical hindcasts (Scaife et al. 2014) that sea ice variability over the eastern Arctic in November can be regarded as a predictability source for winter climate conditions in the Euro-Atlantic sector.

On the other hand, October SIC/BK yields statistically significant skill of SLP over northern Eurasia (Fig. 5a), which might be related to processes that are not present in the relationship between November SIC/BK and the winter NAO (Fig. 5b). Likely associated with the SLP skill, cross-validated hindcasts using October SIC/BK also provide some significant skill for SAT in central Eurasia (Fig. 5c), but not for precipitation (Fig. 5e). These results are in agreement with Mori et al. (2014), who have found that recent cold winters in Eurasia are related to recent reduction of sea ice in the Barents-Kara Seas and more frequent Eurasian blocking, but not to the winter NAO. It is worth noting that the SLP skill of October SIC/BK 
a) MCA-SIC/BKoct $\times$ SLP (dec)

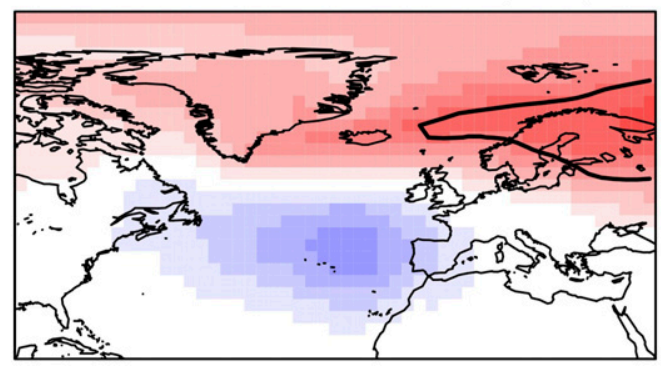

c) MCA-SIC/BKoct X SLP (jan)

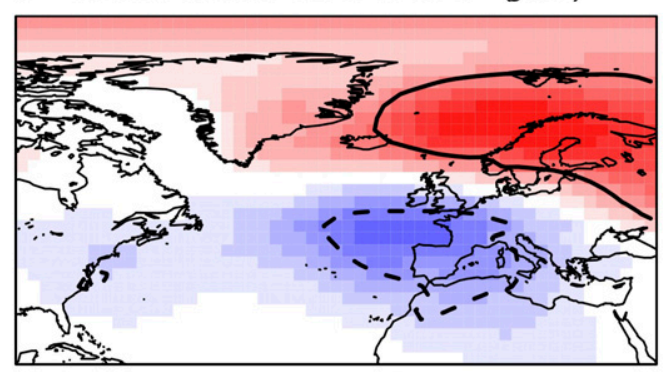

e) MCA-SIC/BKoст x SLP (feb)

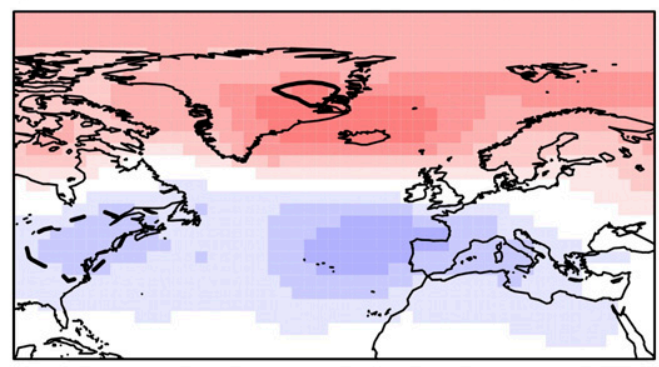

b) MCA-SIC/BK Nov $\times \operatorname{SLP}(\mathbf{d e c})$

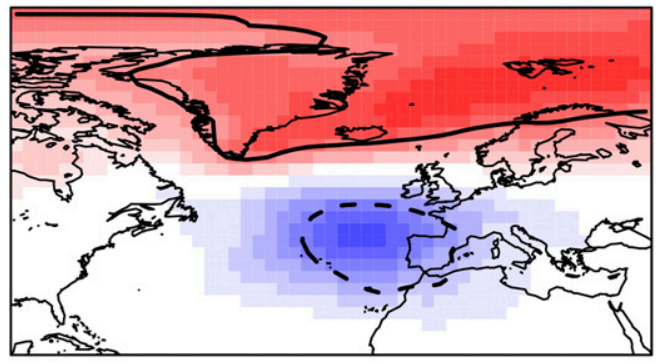

d) MCA-SIC/BKNov $\times$ SLP (jan)

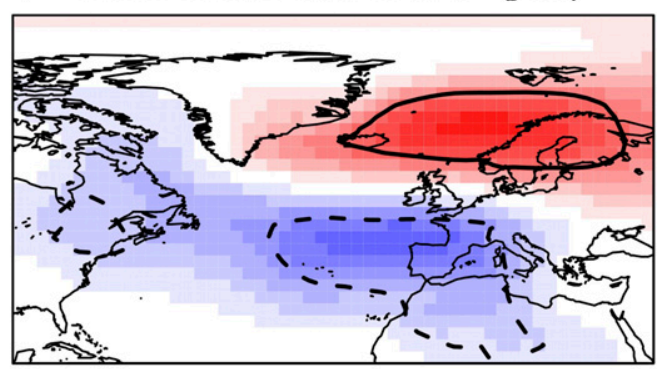

f) MCA-SIC/BKNov $x$ SLP (feb)

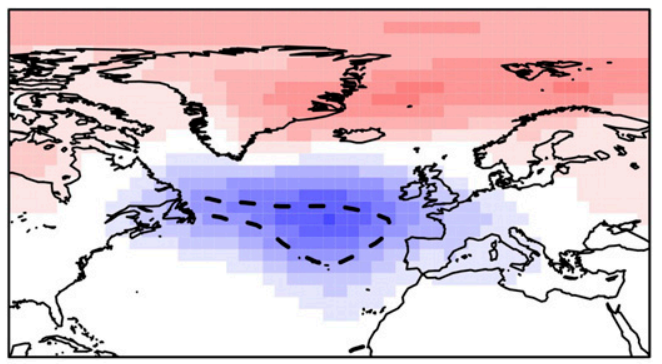

$$
\begin{array}{llllllllllll}
-5 & -4 & -3 & -2 & -1 & 1 & 2 & 3 & 4 & 5
\end{array}
$$

FIG. 4. Regression maps of detrended SLP anomalies (hPa) onto the (left) MCA-SIC/BK ${ }_{\mathrm{OCT}}$ expansion coefficient and (right) MCA-SIC/BK $\mathrm{BOV}_{\mathrm{NOV}}$ expansion coefficient for individual winter months: (a),(b) December, (c),(d) January, and (e),(f) February. Statistically significant areas at 95\% confidence level based on a two-tailed Student's $t$ test are contoured.

over Scandinavia and Siberia (Fig. 5a) resembles the circulation anomaly identified in Mori et al. (2014).

\section{b. Circulation anomalies associated with the November SIC/BK predictor}

To establish a dynamical framework of the November SIC/BK influence on the winter NAO, we compare the anomalous atmospheric circulation associated with the MCA-SIC/BK $\mathrm{NOV}_{\mathrm{N}}$ expansion coefficient to that preceding the winter NAO itself, which can be considered as NAO precursors. For ease of comparison, the negative $\mathrm{NAO}\left(\mathrm{NAO}^{-}\right)$index is considered, whose evolution is inverted from the time series in Fig. $1 \mathrm{~b}$ (solid line). Figure 6 shows correlation maps with this
$\mathrm{NAO}^{-}$index (left panels) and the MCA-SIC/BK $\mathrm{NOV}$ expansion coefficient (right panels) of, from bottom to top, SLP, geopotential height at $200 \mathrm{hPa}$ (Z200; representative of the upper troposphere), and geopotential height at $50 \mathrm{hPa}$ (Z050; representative of the lower stratosphere).

The SLP correlation map of $\mathrm{NAO}^{-}$(Fig. 6e) depicts a tripolar structure, with positive correlations over central Eurasia and negative correlations over Europe and southern Eurasia. The latter suggests a baroclinic structure with height, as revealed by the Z200 correlation map (Fig. 6c). The anomalous anticyclonic circulation over central Eurasia is slightly shifted upstream in the upper troposphere, suggesting some baroclinicity 

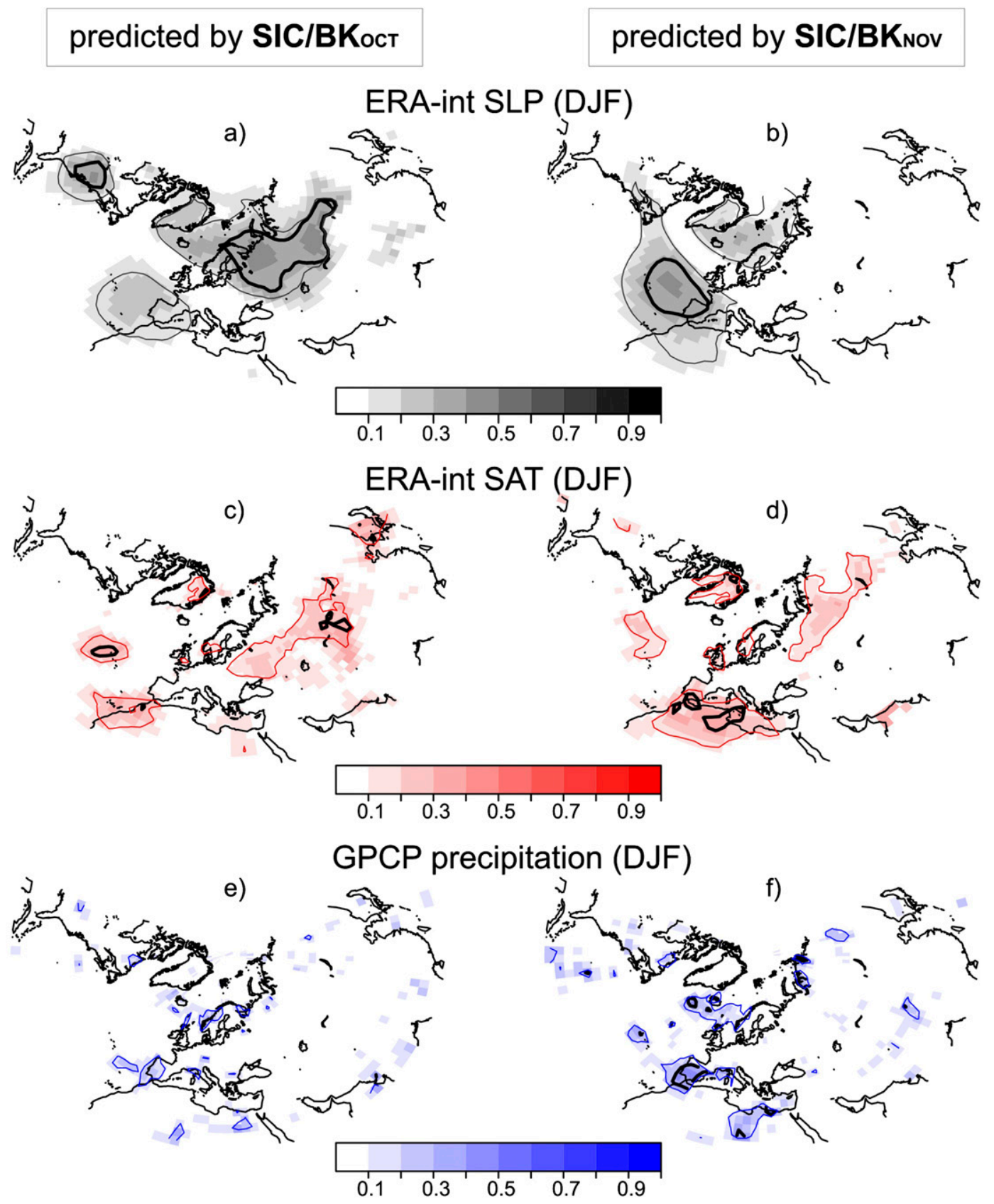

FIG. 5. Cross-validated skill of surface climate (shading): correlation maps between the predicted and observational detrended winter (a),(b) ERA-Int SLP, (c),(d) ERA-Int SAT, and (e),(f) GPCP precipitation anomalies. The crossvalidated hindcasts use MCA applied to eastern Arctic SIC (SIC/BK) in (left) October and (right) November; statistically significant areas at 95\% confidence level based on a one-tailed Student's $t$ test (as only positive correlations indicate skill) are contoured in black; negative correlations are masked out. Areas enclosing statistically significant linear correlation coefficients (thin colored lines), at 95\% confidence level based on a two-tailed Student's $t$ test, of detrended anomalies with the (left) MCA-SIC/BK ${ }_{\mathrm{OCT}}$ expansion coefficient and (right) MCA-SIC/BK ${ }_{\mathrm{NOV}}$ expansion coefficient are shown.

likely associated with a surface boundary forcing (e.g., Honda et al. 2009; Inoue et al. 2012). The eastward extension of this positive SLP anomaly is not statistically significant but is found below an upper-tropospheric cyclonic anomaly over the Lake Baikal region (Figs. 6c,e). It has been shown that Eurasian snow forcing leads to variations in the Siberian high depicting a baroclinic response over this region (Gong et al. 2003, 2004; Cohen et al. 2007; 

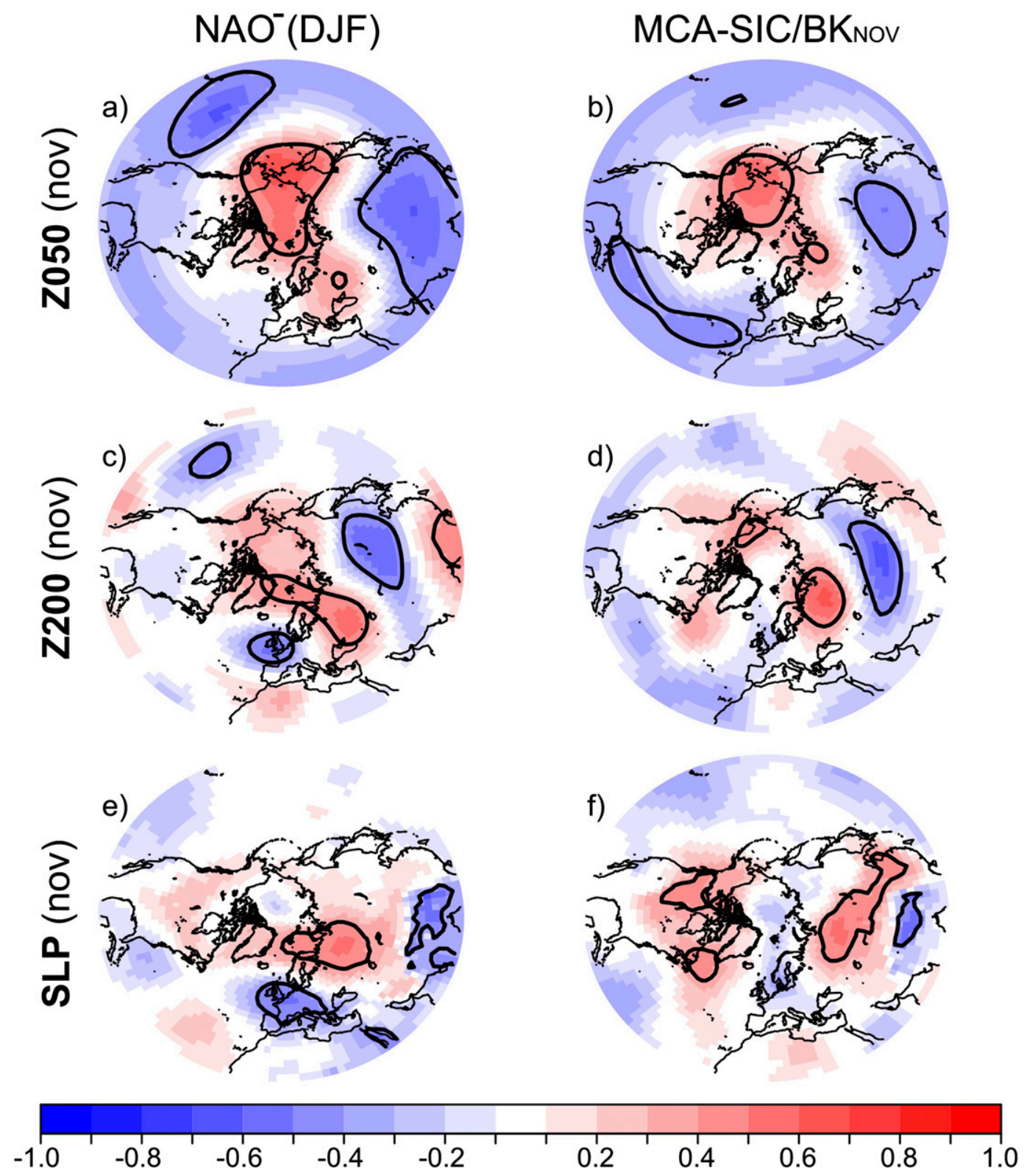

FIG. 6. Correlation maps of detrended geopotential height anomalies at (a),(b) 50 (Z050) and (c),(d) $200 \mathrm{hPa}$ (Z200), and (e),(f) SLP anomalies in November with the (left) winter $\mathrm{NAO}^{-}$index and (right) MCA-SIC/BK $\mathrm{NOV}$ expansion coefficient. Statistically significant areas at $95 \%$ confidence level based on a two-tailed Student's $t$ test are contoured.

Fletcher et al. 2009; Peings et al. 2012). By contrast, there is no clear shift with height in the NAO-related cyclonic anomaly over Europe, suggesting that its barotropic structure is the result of transient-eddy feedback (e.g., Kushnir et al. 2002). The Z200 correlation map of $\mathrm{NAO}^{-}$(Fig. 6c) shows a tripolar structure over Eurasia, which is wavelike. It resembles the wavelike anomaly found by Kuroda and Kodera (1999) to precede a NAO-like pattern. These NAO-related upper-tropospheric anomalies are associated with stationary wave activity from central Europe toward central-eastern Eurasia (Fig. 7a).

The SLP correlation map of MCA-SIC/BK ${ }_{\mathrm{NOV}}$ (Fig. 6f) projects on part of the NAO-related tripolar structure, as only the dipole-like anomaly over Eurasia is statistically significant. It also compares reasonably well with the SLP composite analysis of low-minus-high Arctic sea ice years by Francis et al. (2009). The dipolelike anomaly over Eurasia has a strong resemblance to the November SLP atmospheric response to sea ice 
stationary WAF - 200hPa $\mathrm{NAO}^{-}$(DJF) vs (nov)

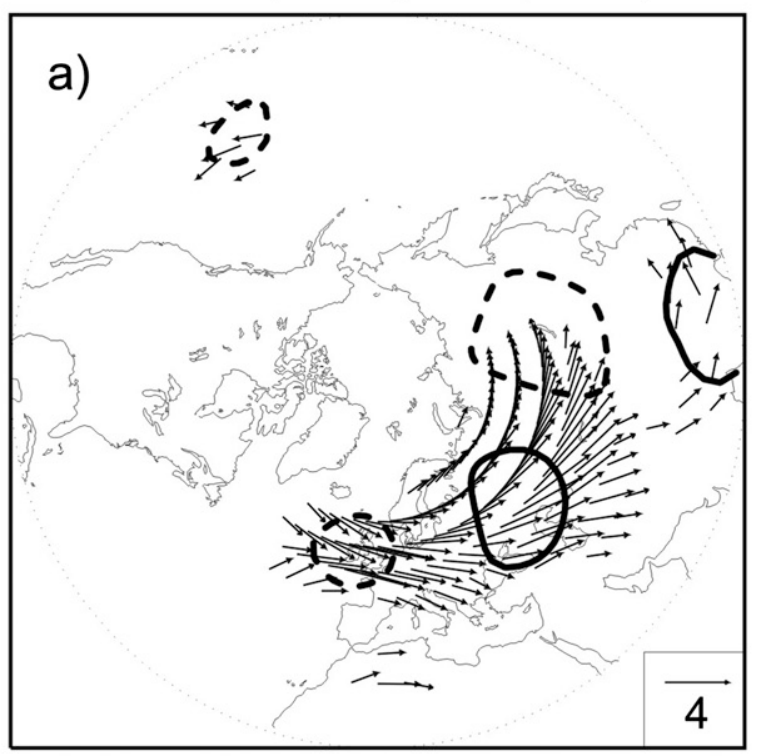

\section{MCA-SIC/BKnov vs (nov)}

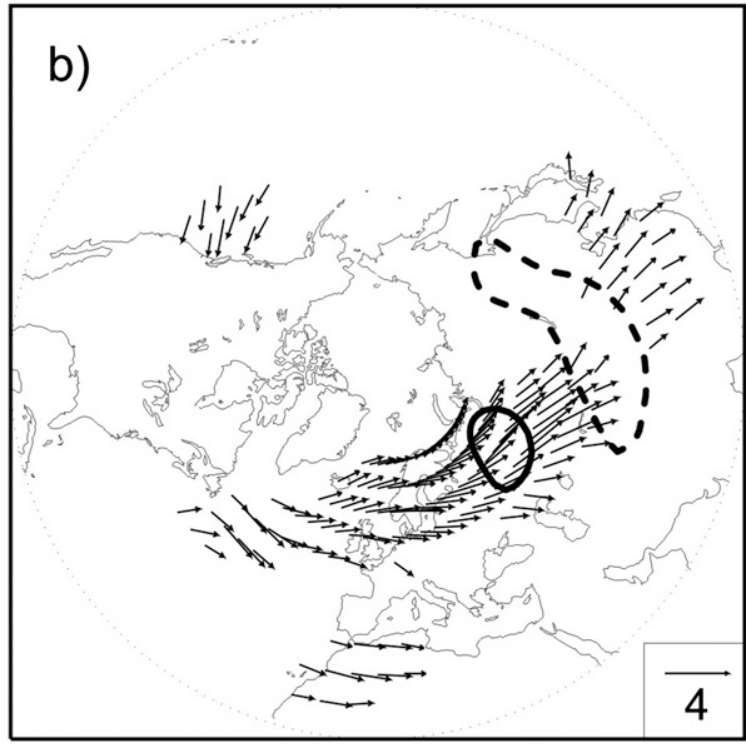

FIG. 7. (a) Horizontal, stationary wave activity flux $\left(\mathrm{m}^{2} \mathrm{~s}^{-2}\right)$ associated with the asymmetric part (departure from zonal mean) of the regression map of detrended Z200 anomalies in November onto the winter $\mathrm{NAO}^{-}$index, and (b) the MCA-SIC/BK $\mathrm{NOV}_{\mathrm{NO}}$ pansion coefficient; shown are anomalies larger than $1 \mathrm{~m}^{2} \mathrm{~s}^{-2}$. The diagnostic has been computed according to Karoly et al. (1989). Overlaid are contours where the corresponding regression map of detrended Z200* anomalies are statistically significant at $95 \%$ confidence level based on a two-tailed Student's $t$ test. changes over the eastern Arctic found by Honda et al. (2009). Associated with November MCA-SIC/BK anomalies there are also statistically significant correlations of SLP over Canada, but they are not statistically significant at the upper troposphere (Figs. 6d,f). The

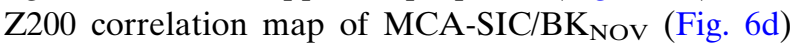
depicts a wavelike anomaly over the Eurasian sector, which is reminiscent of the NAO-related circulation anomaly (Fig. 6c). The two upper-tropospheric centers of action over Eurasia strongly resemble the pattern found by Honda et al. (2009). Their AGCM study indicated that the atmospheric response in November to anomalous sea ice over the Barents-Kara Seas region can be regarded as a stationary Rossby wave train, generated thermally via anomalous heat fluxes. This is in agreement with theoretical arguments (Hoskins and Karoly 1981). Consistent with this interpretation, the upper-tropospheric anomalies associated with MCA$\mathrm{SIC} / \mathrm{BK}_{\mathrm{NOV}}$ are linked to stationary wave activity flux from northern Europe toward central Eurasia (Fig. 7b), which is shifted poleward and with a more marked southward component than that related to $\mathrm{NAO}^{-}$(Fig. 7a). These results lead to conclude that the MCA-SIC/BK $\mathrm{BOV}_{\mathrm{NOV}}$ wavelike anomaly in November, preceding a negative NAO-like pattern by one month, is likely to reflect sea ice forcing from the Barents-Kara Seas.

This is further assessed in Fig. 8, which shows regression maps of anomalous surface turbulent heat flux (sensible plus latent heat flux; upward is positive) in lead and lag conditions onto the MCA-SIC/BK ${ }_{\mathrm{NOV}}$ expansion coefficient. In September (see the appendix; Fig. A1f), there are no statistically significant anomalies over the eastern Arctic and their amplitude is weak. In October (Fig. 8a), there are negative heat flux anomalies over the open-water areas of Norwegian Sea and central Barents Sea, indicating that the ocean is losing less energy (i.e., retaining more heat), which likely leads to sea ice melting at the sea ice edge. This anomalous downward heat flux seems induced by southwesterly air advection over the region (not shown). In November (Fig. 8b), negative heat flux anomalies remain over the central-southern Barents Sea, over the open-water area, consistent with southerly air advection (Fig. 6f). However, there are positive heat flux anomalies over the northern Barents Sea and southern Kara Sea, where sea ice is reduced (cf. Fig. 3a), which indicates that the heat release to the atmosphere has increased. This anomalous upward heat flux is associated with a large atmospheric warming between 700 and $1000 \mathrm{hPa}$ at $65^{\circ}-80^{\circ} \mathrm{N}$ (Fig. $8 \mathrm{~d}$ ). These results suggest that the tropospheric circulation anomalies associated with

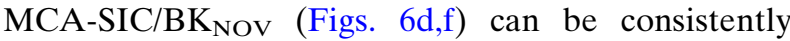




\section{turbulent heat flux [shf+lhf]}

a) MCA-SIC/BK $K_{\text {Nov }} x$ (oct)

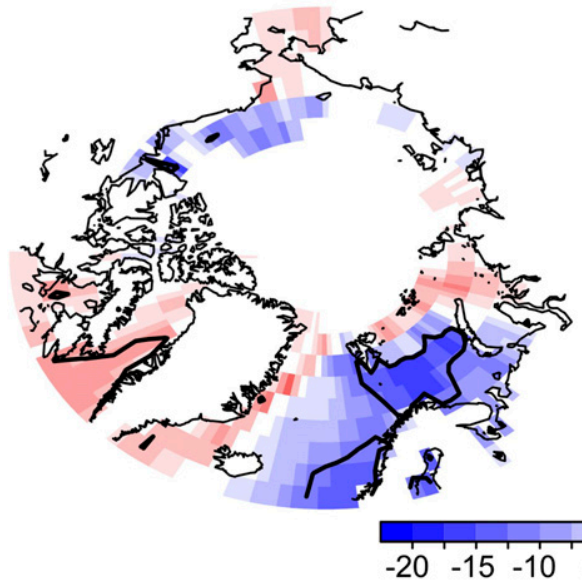

c) MCA-SIC/BKNov $x(\mathbf{d e c})$

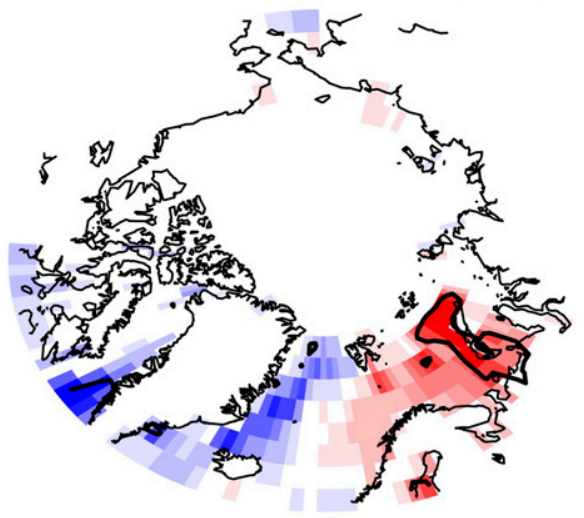

b) MCA-SIC/BK NOV $\times($ nov $)$

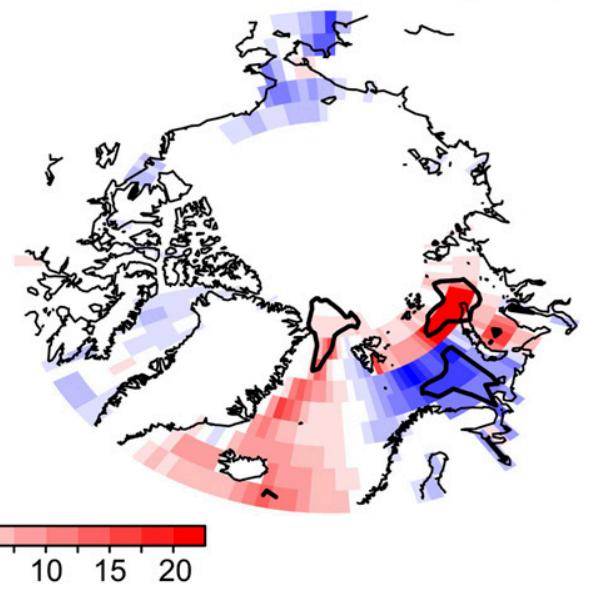

MCA-SIC/BKnov x T[60E-90E] (nov)

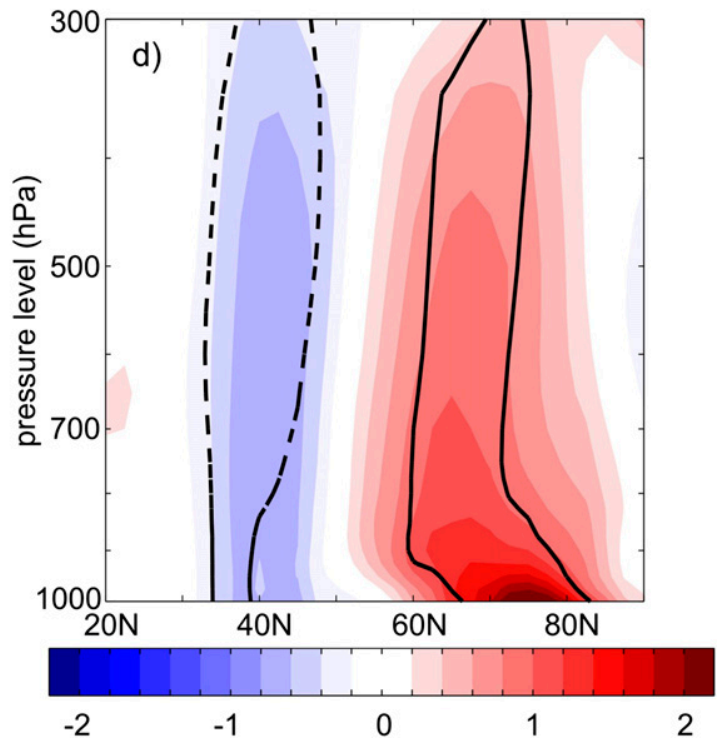

FIG. 8. Regression maps of detrended turbulent heat flux anomalies (sensible heat plus latent heat; $\mathrm{W} \mathrm{m}^{-2}$, upward is positive) in (a) October, (b) November, and (c) December onto the MCA-SIC/BK $\mathrm{NOV}_{\text {expansion co- }}$ efficient. (d) Regression cross section, pressure level vs latitude, of detrended air temperature anomalies zonally averaged over $60^{\circ}-90^{\circ} \mathrm{E}\left({ }^{\circ} \mathrm{C}\right)$ in November onto the MCA-SIC/BK $\mathrm{NOV}$ expansion coefficient. Statistically significant areas at $95 \%$ confidence level based on a two-tailed Student's $t$ test are contoured.

interpreted as atmospheric response to sea ice changes. However a cautionary note is required, since the in-phase correlation cannot distinguish between atmospheric forcing and response. Although we cannot conclusively demonstrate causality from observations, it is worth noting that Honda et al. (2009) found similar heat flux anomalies in their AGCM response to prescribed SIC anomalies. In December (Fig. 8c), once the negative NAO is established (Figs. $3 \mathrm{~b}$ and $4 \mathrm{~b}$ ), the positive anomalies over the Barents Sea (in open waters) and the negative ones over the Davis
Strait-Labrador Sea region illustrate its well-known fingerprint in sea ice variability (e.g., Deser et al. 2000) -in particular, with positive (negative) heat flux anomalies cooling (warming) the ocean and leading to sea ice increase (retreat).

A plausible mechanism linking SIC/BK-related circulation anomalies in November and the establishment of the winter NAO involves a stratospheric pathway. Indeed, geopotential height anomalies in the Eurasian sector have been identified as source of vertical 
propagation of planetary waves (Kuroda and Kodera 1999; Garfinkel et al. 2010; Kolstad and Charlton-Perez 2011), producing circulation anomalies in the stratospheric polar vortex that subsequently descend to the troposphere and project on the NAO (e.g., Polvani and Waugh 2004). Different mechanisms have been proposed to explain this downward propagation of anomalies (see Gerber et al. 2012; Tomassini et al. 2012 for review). The Z050 correlation map of $\mathrm{NAO}^{-}$(Fig. 6a) shows statistically significant correlations over the polar cap. This Z050 pattern projects on an elongated vortex, with positive correlations over the northern North Pacific and eastern Arctic basins, which suggests the presence of wavenumber-2 anomalies (Charlton and Polvani 2007; Martius et al. 2009). Consistently, Mitchell et al. (2013) have shown that a weakened polar vortex with a wavenumber- 2 component is followed by a negative NAO-like signature at surface. The Z050 correlation

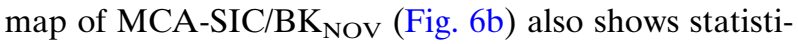
cally significant correlations over the polar cap, displaying a wavenumber-2 structure as well, but slightly shifted to the east. This result indicates that negative sea ice anomalies over the Barents-Kara Seas in November are associated with a weakened polar vortex, which precedes the establishment of a negative NAO-like pattern (Figs. 3 and 6b).

To assess the role played by the Eurasian wavelike anomaly in modulating the polar vortex strength, the zonally averaged meridional eddy heat flux, $\left[v^{*} T^{*}\right]$ is analyzed. This diagnostic is proportional to wave activity propagating from the troposphere into the stratosphere, as it is equivalent to the vertical component of the conventional Eliassen-Palm flux (e.g., Nishii et al. 2009). Figure 9a (black line) shows that, prior to a negative phase of the winter NAO, wave forcing of the polar vortex is enhanced in November. This amplification takes place, with statistical significance, between middle and subpolar latitudes (Fig. 9a, black symbols), and it illustrates that upward wave activity propagation precedes the establishment of the NAO, as shown by Kuroda and Kodera (1999) among others. Figure 9a (red symbols) also shows that

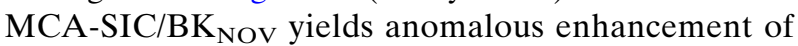
upward wave activity between middle and subpolar latitudes.

The precursors of the weakened polar vortex are in the troposphere. When tropospheric anomalies reinforce (i.e., are in phase with) the climatological wave pattern, wave driving of the polar vortex is expected to increase, and conversely when the tropospheric anomalies are out of phase with the climatological wave pattern (Garfinkel et al. 2010; Kolstad and Charlton-Perez 2011). Climatological planetary waves are enhanced a) $\left[\mathrm{v}^{*} \mathrm{~T}^{*}\right]$ at $100 \mathrm{hPa}(\mathrm{nov})$

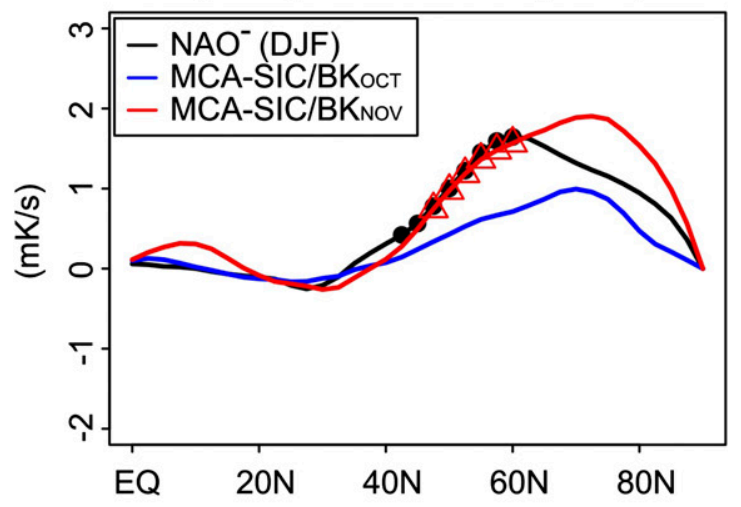

b)
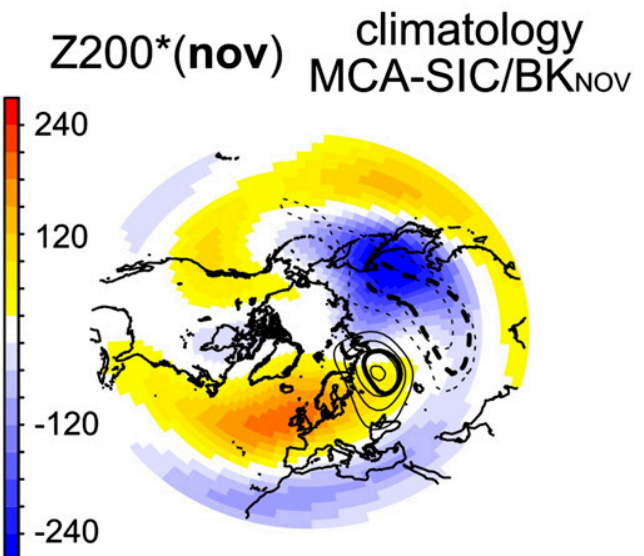

c) $v^{*} T^{* 100}$ (nov) $\begin{gathered}\text { climatology } \\ \text { MCA-SIC/BK }\end{gathered}$

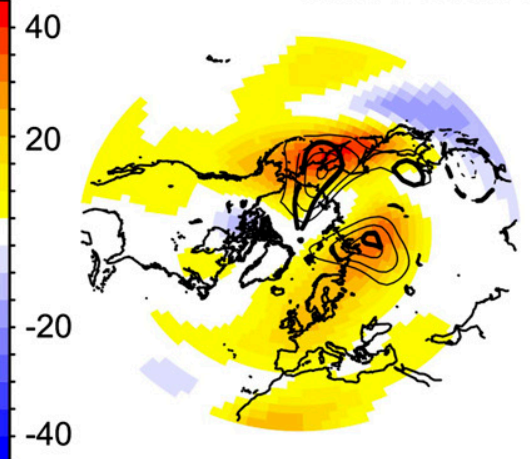

FIG. 9. (a) Regression of detrended zonal-mean meridional eddy heat flux anomalies $\left(\mathrm{K} \mathrm{m} \mathrm{s}^{-1}\right)$ in November onto the winter $\mathrm{NAO}^{-}$ index (black line), the MCA-SIC/BK $\mathrm{BCT}_{\mathrm{O}}$ expansion coefficient (blue line), and the MCA-SIC/BK $\mathrm{BOV}_{\mathrm{N}}$ expansion coefficient (red line). The diagnostic is computed at $100 \mathrm{hPa}$ and is based on daily data (see section 2). Statistical significance at $95 \%$ confidence level based on a two-tailed Student's $t$ test is indicated with symbols. Climatology of the (b) asymmetric part (departure from zonal mean) of Z200 (Z200*, shading; m) and (c) meridional eddy heat flux $\left(v^{*} T^{*}\right)$ at $100 \mathrm{hPa}$ (shading; $\mathrm{K} \mathrm{m} \mathrm{s}^{-1}$ ) in November. Regression maps (thin contours) of detrended Z200* [contour interval $(\mathrm{CI})=10 \mathrm{~m}$ ] and $v^{*} T^{*}$ at $100 \mathrm{hPa}$ $\left(\mathrm{CI}=2.5 \mathrm{~K} \mathrm{~m} \mathrm{~s}^{-1}\right)$ anomalies onto the MCA-SIC/BK $\mathrm{NOV}$ expansion coefficient in (b) and (c), respectively; only statistically significant areas at 95\% confidence level based on a two-tailed Student's $t$ test are shown (thick contours). 
by a low over the eastern Eurasian sector, where the climatological wavenumber 1 and wavenumber 2 are both low, and by a high over the western Eurasian sector, where climatological wavenumber 1 and wavenumber 2 are both high (Garfinkel et al. 2010). Figure 9b (shading) displays the full field of the Z200 zonal asymmetries (Z200*) climatology in November; it can be seen that the $2200^{*}$ regression map of $\mathrm{MCA}-\mathrm{SIC} / \mathrm{BK}_{\mathrm{NOV}}$ (Fig. 9b, contours) constructively interferes with the climatological wave pattern over Eurasia. This enhancement in amplitude would lead to amplified meridional heat fluxes, thereby increasing the upward propagation of wave activity into the stratosphere (Kolstad and Charlton-Perez 2011). The spatial distribution of November $v^{*} T^{*}$ depicts the key regions in the tropospheric wave driving of the stratospheric polar vortex. In agreement with Newman and Nash (2000), the climatology of $v^{*} T^{*}$ (Fig. 9c, shading) shows two main regions contributing to the positive zonal-mean eddy heat flux, reflecting poleward warm air advection over eastern Eurasia-northwestern North Pacific and equatorward cold air advection over central Eurasia-northeastern Europe. The regression map of $\mathrm{MCA}-\mathrm{SIC} / \mathrm{BK}_{\mathrm{NOV}}$ (Fig. 9c, contours) shows that the enhanced $v^{*} T^{*}$, associated with positive $\left[v^{*} T^{*}\right]$ anomalies (Fig. 9a, red line), takes place over eastern Eurasia and central Eurasia. Hence, the wavelike anomaly across Eurasia in November associated with MCA-SIC/BK $\mathrm{NOV}_{\mathrm{N}}$ reinforces the climatological wave pattern amplifying the meridional eddy heat flux and, in turn, the injection of tropospheric wave activity into the stratosphere.

Figure 10 illustrates the stratospheric pathway described above. Shown are correlation profiles of daily geopotential height anomalies area averaged over the polar cap $\left(60^{\circ}-90^{\circ} \mathrm{N}\right)$ with the winter $\mathrm{NAO}^{-}$index (Fig. 10a) and the MCA-SIC/BK $\mathrm{NOV}_{\mathrm{N}}$ expansion coefficient (Fig. 10c). The correlation profile of $\mathrm{NAO}^{-}$ shows that the polar vortex is weakened at the lower stratosphere in November, and that some anomalies penetrate farther toward the upper stratosphere reaching the 1-hPa level in early December, while at the same time other anomalies descend, reaching the surface in and after middle-to-late December (Fig. 10a). The correlation profile of $\mathrm{MCA}-\mathrm{SIC} / \mathrm{BK}_{\mathrm{NOV}}$ suggests that the polar vortex at the lower stratosphere is weakened slightly later, the upward propagating anomalies reach the upper stratosphere slightly faster, but the downward propagating anomalies reach the surface only in middle-to-late December (Fig. 10c). The amplitude of the correlations at tropospheric levels with MCA-SIC/ $\mathrm{BK}_{\mathrm{NOV}}$ in midwinter is weaker than that with $\mathrm{NAO}^{-}$, although the structure is very similar, including the maximum around $100-300 \mathrm{hPa}$ in late January/early
February. The lack of statistical significance for this maximum at lower-tropospheric levels (Fig. 10c) is because the NAO-like signature related to MCA-SIC/ $\mathrm{BK}_{\mathrm{NOV}}$ is more pronounced at North Atlantic middle/ subpolar latitudes than at polar latitudes (Figs. 4d,f); at midtropospheric levels, the correlation maps of MCA-

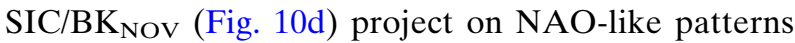
(Fig. 10b). Besides, one has to bear in mind that the NAO-related correlations shown in Fig. 10a include contributions from internally generated variability and other forcings.

It is expected that when descending anomalies reach the upper troposphere in the North Atlantic sector they trigger the positive feedback from transient eddies that can amplify regional circulation anomalies and help to settle the NAO pattern in winter (e.g., Thompson et al. 2003). To assess the role played by tropospheric dynamics, the transient-eddy momentum flux $\left(u^{\prime} v^{\prime}\right)$ and PKE at $200 \mathrm{hPa}$ are considered; the former encapsulates the interaction between transient eddies and mean flow through barotropic processes, and the latter measures the intensity and location of transient eddies, namely the storm-track activity (e.g., Hoskins et al. 1983; Trenberth 1986). As also shown for $\mathrm{NAO}^{-}$(Figs. 11b,e), albeit with overall weaker amplitude, the correlation maps of $\mathrm{MCA}-\mathrm{SIC} / \mathrm{BK}_{\mathrm{NOV}}$ (Figs. 11c,f) depict a dipole-like anomaly associated with latitudinal shifts of the North Atlantic eddy-driven jet (e.g., Rivière and Orlanski 2007). The correlation map of $u^{\prime} v^{\prime}$ (Fig. 11c) indicates that transient-eddy momentum transport tends to decelerate the westerly flow north of the North Atlantic jet exit region (negative correlations over northern Europe) and to accelerate it to the south (positive correlations over northern Africa). These anomalies thus reflect a southward shift of the North Atlantic storm track (Fig. 11f), which is closely linked to the negative NAO-like pattern (Fig. 3b) associated with the November SIC/BK anomalies (Fig. 3a).

\section{c. Circulation anomalies associated with the October SIC/BK anomalies}

Recall that SIC/BK in October yields some positive skill of the winter NAO index, but no statistically significant skill for surface variables over the Euro-Atlantic sector (SLP, SAT, or precipitation; Figs. 5a,c,e). The aim here is to briefly describe the distinct circulation anomalies in November associated with MCA-SIC/BK compared to those associated with $\mathrm{MCA}-\mathrm{SIC} / \mathrm{BK}_{\mathrm{NOV}}$ (section 3b). Figure 12 shows correlation maps of November SLP (Fig. 12c) and Z200 (Fig. 12a) with the MCA-SIC/BK ${ }_{\text {OCT }}$ expansion coefficient. No significant correlations are found at stratospheric levels 


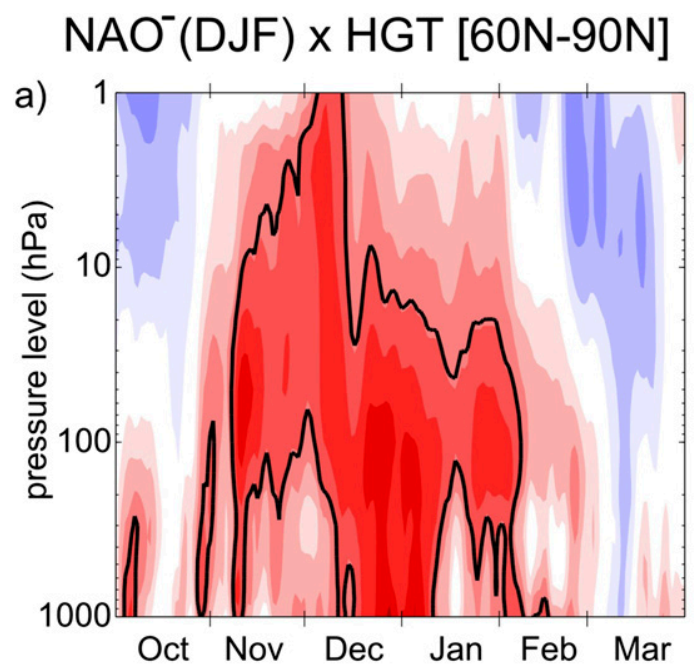

MCA-SIC/BKNov $x$ HGT [60N-90N]

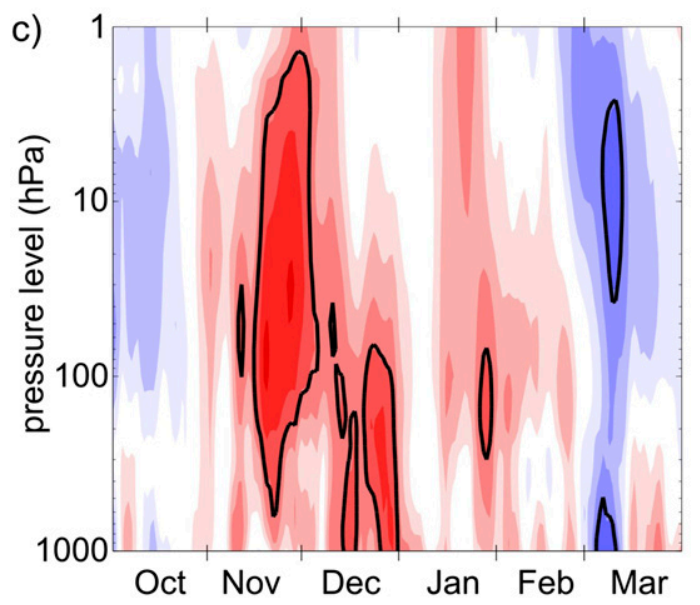

b)

$$
\mathrm{NAO}^{-}(\mathrm{DJF}) \times \mathrm{Z} 500
$$

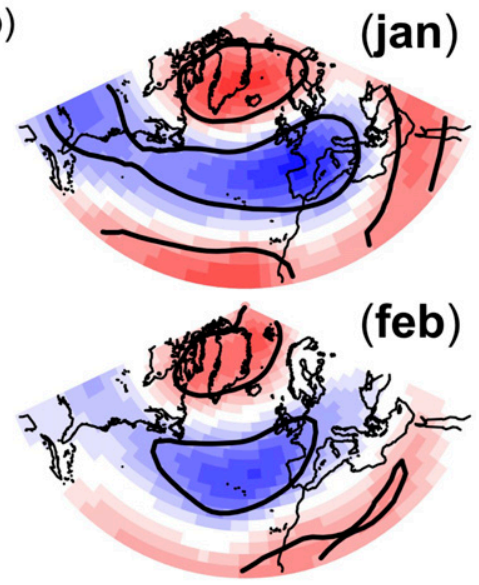

MCA-SIC/BKNov $x$ Z500

d)
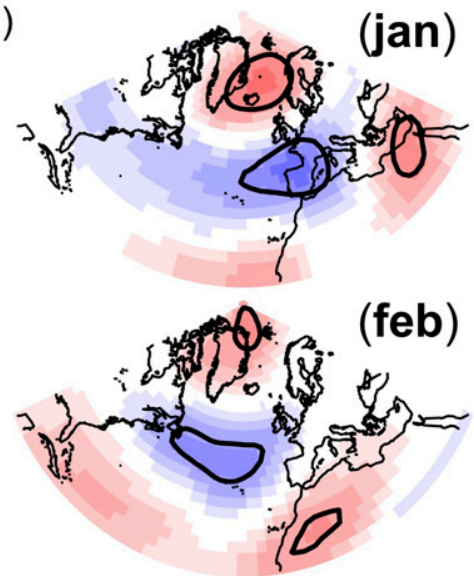

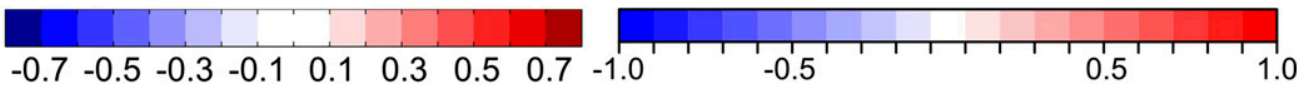

FIG. 10. (left) Correlation sections of detrended geopotential height anomalies averaged over the polar cap $\left(60^{\circ}-\right.$ $90^{\circ} \mathrm{N}$ ) with (a) the winter $\mathrm{NAO}^{-}$index and (c) the MCA-SIC/BK $\mathrm{NOV}$ expansion coefficient; the time axis is in daily values from 1 Oct to 31 Mar. (right) Correlation maps of detrended geopotential height anomalies at $500 \mathrm{hPa}(\mathrm{Z} 500)$

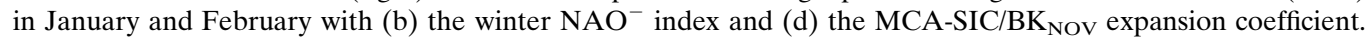
Statistically significant areas at $95 \%$ confidence level based on a two-tailed Student's $t$ test are contoured.

(not shown); accordingly, MCA-SIC/BK ${ }_{\mathrm{OCT}}$ does not significantly affect the wave forcing of the polar vortex in November (Fig. 9a, blue line). This indicates that the influence of October SIC/BK anomalies on the winter North Atlantic-European atmospheric circulation relies on tropospheric dynamics, which is consistent with the findings of Kodera and Kuroda (2000). The SLP correlation map already displays a negative NAO-like signature in November, with negative correlations at midlatitudes and positive correlations at subpolar latitudes (Fig. 12c). The Z200 correlation map shows a similar pattern (Fig. 12a). The statistical significance of these anomalies is, however, quite limited, and the mechanism responsible for this dipole-like anomaly upstream the sea ice anomalies in the BarentsKara Seas is unclear. The stationary wave activity related to the $\mathrm{Z} 200$ anomalies shows a regional signal, very different from that associated with MCA-SIC/BK $\mathrm{BOV}_{\mathrm{NO}}$ (cf. Figs. $7 \mathrm{~b}$ and $12 \mathrm{~b}$ ). The transient-eddy activity is altered at North Atlantic midlatitudes (Fig. 12d), showing a weakening in the storm track. This suggests that the positive eddy feedback could contribute to maintain the atmospheric anomalies in the troposphere and establish a negative NAO-like pattern into winter 

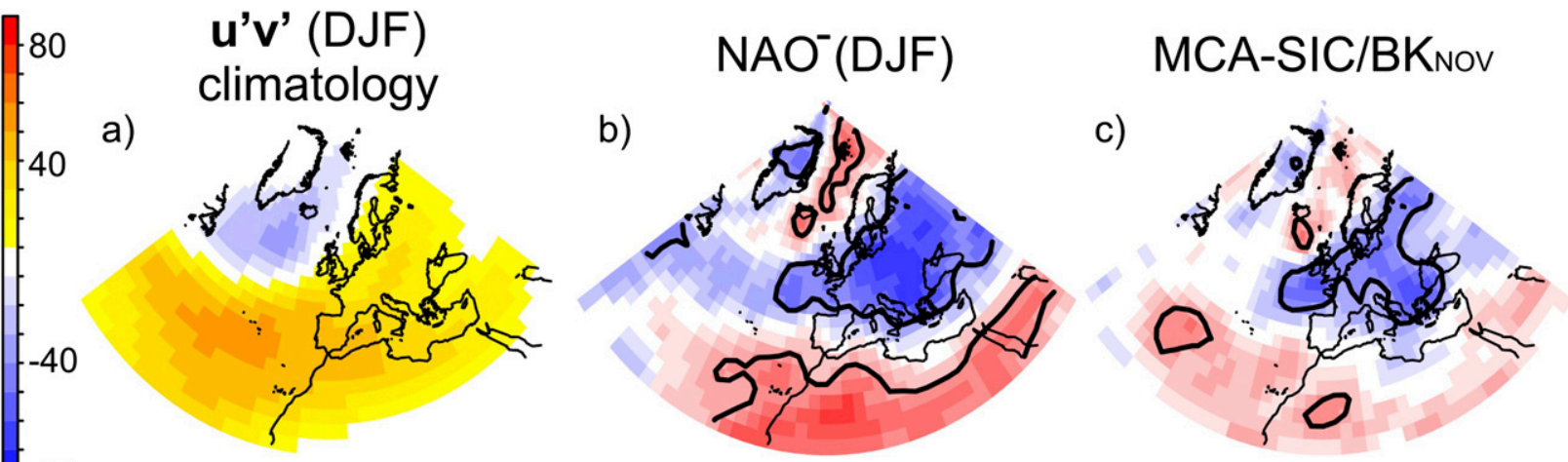

$-80$

PKE (DJF) climatology
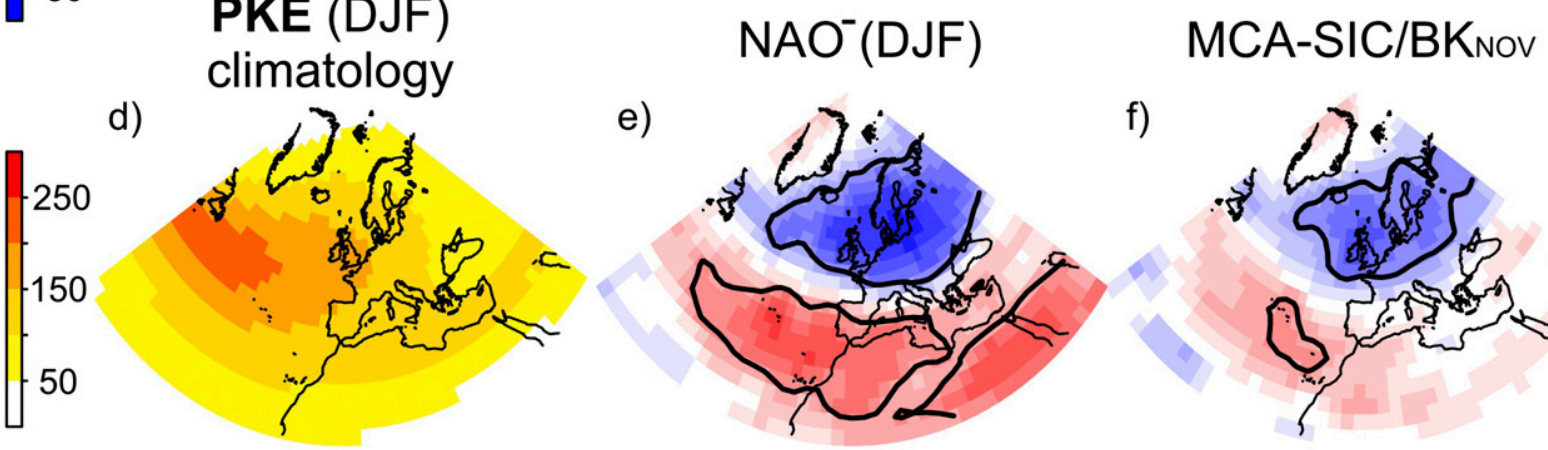

e)

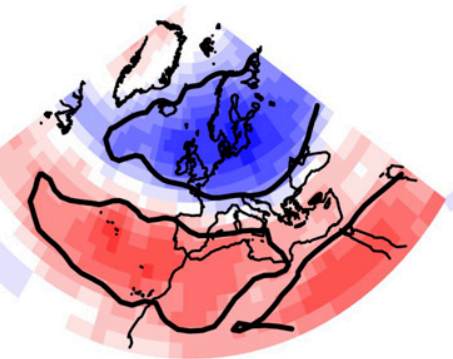

f)

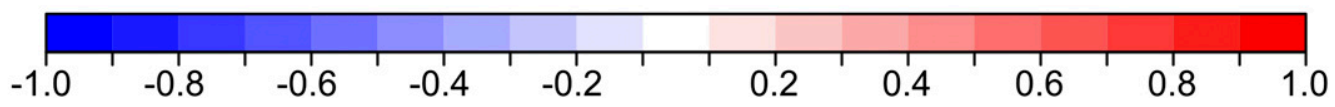

FIG. 11. Climatology of the winter (a) high-pass-filtered eddy momentum flux $\left(u^{\prime} v^{\prime} ; \mathrm{m}^{2} \mathrm{~s}^{-2}\right)$ and (d) PKE ( $\left.\mathrm{m}^{2} \mathrm{~s}^{-2}\right)$ over the period 1979 / 80-2012/13. Also shown are correlation maps of (b),(c) detrended $u^{\prime} v^{\prime}$ and (e),(f) PKE anomalies with the (b),(e) winter NAO ${ }^{-}$index and

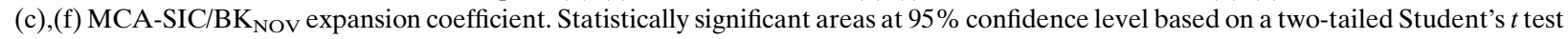
are contoured.

(e.g., Cassou et al. 2004); however, although plausible, this speculation is to be taken with caution.

From this analysis, the question emerges on why the atmospheric circulation anomalies associated with MCA-SIC/BK ${ }_{\mathrm{OCT}}$ and MCA-SIC/BK $\mathrm{BOV}_{\mathrm{NO}}$ are that different, when one of the premises of extended-range predictability is the persistence of the boundary forcing. The regression map of November SIC anomalies onto the MCA-SIC/BK ${ }_{\mathrm{OCT}}$ (Fig. 13a) and MCA-SIC/BK ${ }_{\mathrm{NOV}}$ (Fig. 13b) expansion coefficients shows that SIC/BK anomalies dominate the pattern over the whole Arctic in both cases, displaying maximum loadings around the climatological sea ice edge, as discussed in section 3a. It follows that the spatial distribution of the SIC anomalies cannot explain the discrepancy among the related atmospheric circulation anomalies. However, the amplitude of the negative November SIC anomalies is almost double:

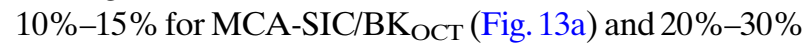

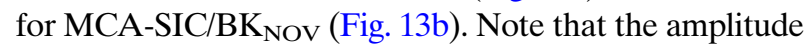

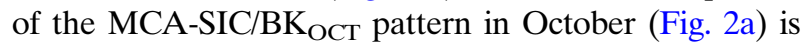
comparable to that of the MCA-SIC/BK $\mathrm{NOv}_{\mathrm{N}}$ in November
(Figs. 3a and 13b). The persistence of detrended SIC anomalies from October to November is marked over the northern Barents Sea and southern Kara Sea along the seasonal expansion of the sea ice edge, and also in the interior ice pack and over the Greenland Sea (Fig. 14a). Note that the persistence of September SIC/BK anomalies into November is, on the contrary, negligible (see the appendix; Fig. A1b). It suggests that there is a strong relationship between the anomalous state of SIC/BK in October and that in November, which might explain the similar skill in the NAO hindcasts. Yet, the overall positive turbulent heat flux anomalies associated with MCA-SIC/BK ${ }_{O C T}$ in November over the eastern Arctic (Fig. 14c), including the new ice-free oceanic areas, implies that there is a heat release to the atmosphere tending to cool the surface. This damping would decrease the sea ice reduction in November from MCA-SIC/BK ${ }_{\mathrm{OCT}}$, as compared to the MCA-SIC/BK $\mathrm{BOV}_{\mathrm{N}}$ pattern (Fig. 13). Hence, the stronger amplitude of the MCA-SIC/BK $\mathrm{BOV}_{\mathrm{NO}}$ pattern requires additional contributions apart from SIC/BK 


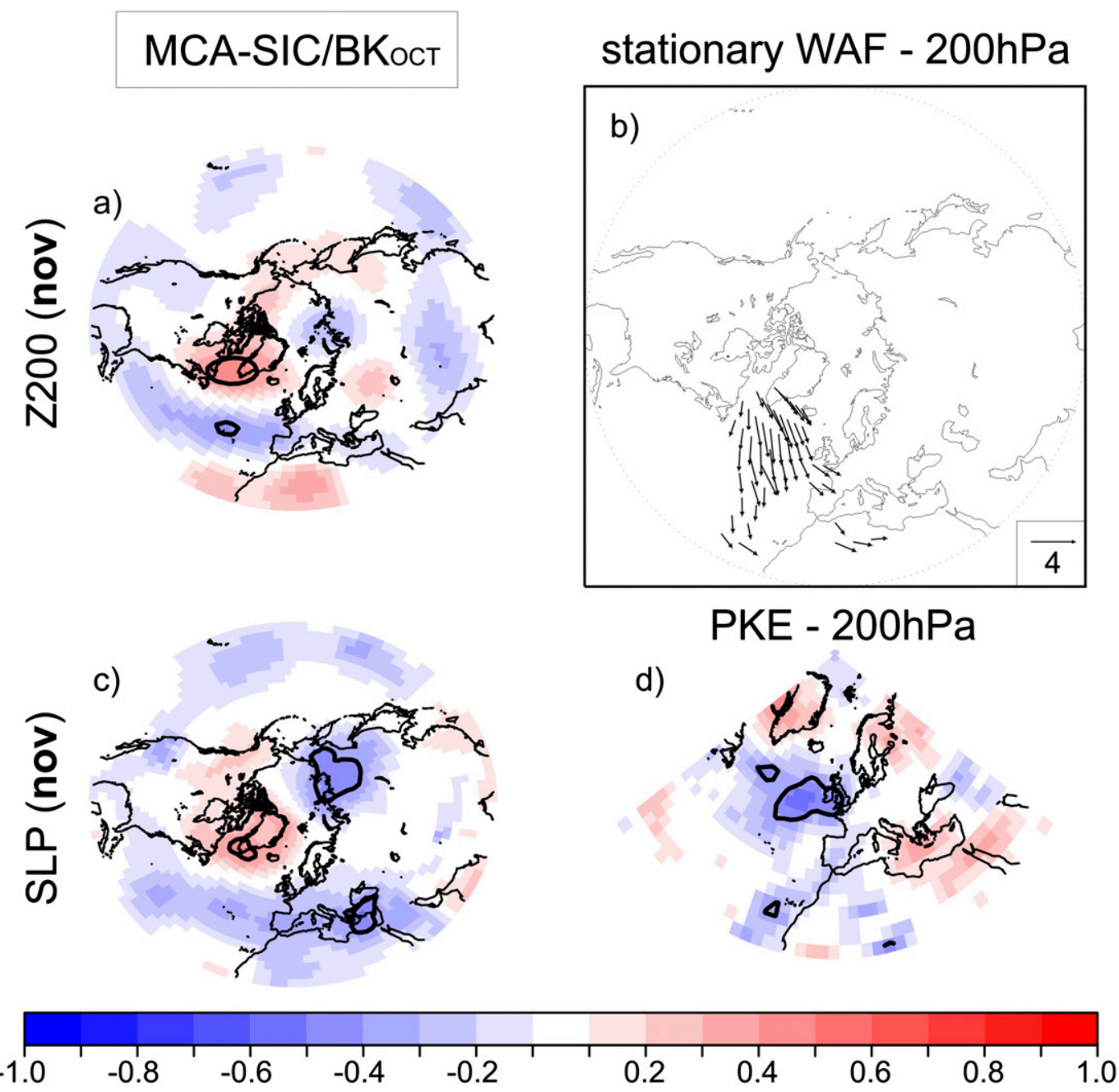

FIG. 12. Correlation maps of (a) Z200, (c) SLP, and (d) PKE anomalies in November with the MCA-SIC/BK OCT $_{\text {OC }}$ expansion coefficient; statistically significant areas at $95 \%$ confidence level based on a two-tailed Student's $t$ test are contoured. (b) Horizontal, stationary wave activity flux $\left(\mathrm{m}^{2} \mathrm{~s}^{-2}\right)$ associated with the asymmetric part (departure from zonal mean) of the regression map of detrended Z200 anomalies in November onto the MCA-SIC/BK OCT expansion coefficient; shown are anomalies larger than $1 \mathrm{~m}^{2} \mathrm{~s}^{-2}$.

anomalies in October, such as the local atmospheric forcing discussed in section $3 b$. In accordance with this line of reasoning, we note that the correlation between the MCA-SIC/BK ${ }_{\mathrm{OCT}}$ and MCA-SIC/BK ${ }_{\mathrm{NOV}}$ expansion coefficients is only 0.59 . This is in agreement with previous works suggesting that distinct mechanisms, or strengths of the mechanisms, driving sea ice edge changes in the Arctic operate in different months (e.g., Tang et al. 2013; Germe et al. 2014).

\section{Conclusions and implications}

The aim of this work has been to further document the influence of interannual variability in autumn Arctic sea ice concentration (SIC) on the winter (DJF)
Euro-Atlantic sea level pressure (SLP), and to explore the predictability of the winter European climate based on this covariability. We consider Arctic SIC in separate autumnal months, September-November, during the 1979/80-2012/13 period. Following previous studies, targeted maximum covariance analysis (MCA) has been performed using SIC over the eastern Arctic, whose loadings are over the Barents-Kara Seas region (SIC/ $\mathrm{BK})$. The results indicate that the leading covariability mode using September SIC/BK is not statistically significant. Using October or November SIC/BK, in both cases, negative SIC anomalies (i.e., sea ice reduction) are followed by a negative NAO-like SLP pattern. The MCA modes are significant, although their expansion coefficients have a relatively low correlation $(0.5-0.6)$. Both 
MCA-SIC/BKост x SIC (nov)

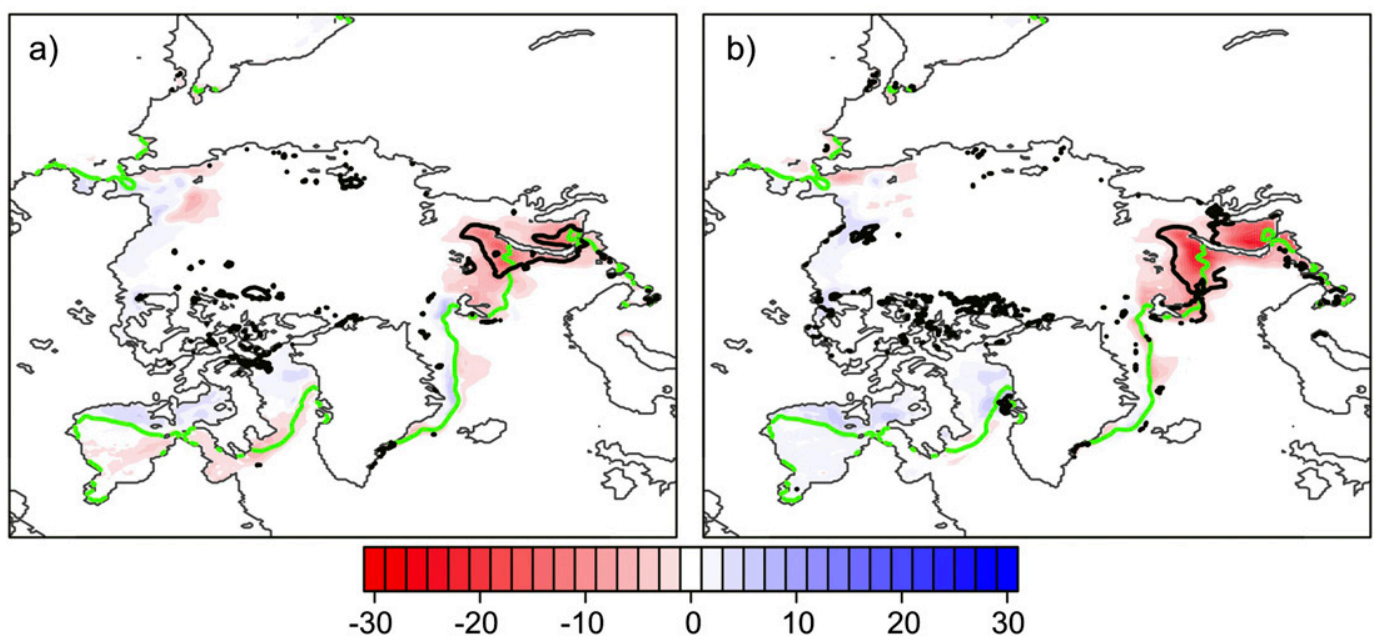

FIG. 13. Regression maps of detrended Arctic SIC anomalies (\%) in November onto the (a) MCA-SIC/BK ${ }_{\text {OCT }}$ expansion coefficient and (b) MCA-SIC/BK $\mathrm{NOV}_{\mathrm{N}}$ expansion coefficient; green contours indicate the climatological sea ice edge, estimated by the $25 \%$ fraction. Statistically significant areas at $95 \%$ confidence level based on a twotailed Student's $t$ test are contoured.

October and November SIC/BK anomalies provide a cross-validated NAO skill of 0.3 , which is not significant at $95 \%$ confidence level (taking into account the autocorrelation of the NAO index), but the score is at the limit for further practical usage (e.g., Johansson 2007). However, only November SIC/BK yields statistically significant cross-validated skill of surface air temperature and precipitation over some regions of Europe, consistently with its statistically significant crossvalidated skill of SLP over the North Atlantic basin. Hence, our results suggest that only November SIC anomalies in the Barents-Kara Seas could be considered as a potential source of predictability for the winter Euro-Atlantic climate. We note that, although there are large areas of significant linear correlation with the MCA-SIC/BK expansion coefficient, the prediction skill is limited.

We have investigated the processes underlying this predictability, and a dynamical framework to address the lagged influence on the winter NAO has been established. Statistical analysis suggests that November SIC anomalies in the Barents-Kara Seas are associated with a Rossby wave train-like anomaly crossing Eurasia, which affects vertical wave activity modulating the stratospheric polar vortex strength. These changes are followed by downward propagation of anomalies that impact transient-eddy feedback at the upper troposphere, helping to settle and maintain the winter NAO at surface. Our results are in general agreement with the observational analysis by King et al. (2015). Targeted modeling efforts are required to support the teleconnection dynamics and fully establish causality links in response to November SIC/ BK anomalies. On the other hand, no clear dynamical signal has been found in association with October SIC/ BK anomalies. This suggests that the winter NAO skill based on October SIC/BK primarily results from its persistence into November, when the sea ice driving is efficient. This could also explain why no skill was found for September SIC/BK, since September SIC/ BK anomalies persist only until October, but not into November.

This work, and particularly the link between November SIC/BK anomalies and the winter North Atlantic-European atmospheric circulation, brings further evidence that low-frequency variability of the winter NAO can be in part driven by changes in surface boundary conditions, thus enhancing its potential predictability. The one-month lagged influence identified here, involving a stratospheric pathway, provided some prediction skill for the winter Euro-Atlantic climate, showing the first hint that empirical forecasts based on Arctic sea ice could be skillful. Prospects for seasonal climate prediction are marked, since initializing (in dynamical) or incorporating (in statistical) late-autumn Arctic sea ice variability in the prediction systems could improve their skill at forecasting the surface winter climate in Europe. Scaife et al. (2014) have encouragingly shown that SIC anomalies over the eastern Arctic in November represent an actual predictability source for the winter Euro-Atlantic climate in dynamical hindcasts. The isolated effect of realistic sea ice initialization on the forecast quality remains to be assessed (Doblas-Reyes 
a) $\mathrm{SIC} / \mathrm{BK}$ (oct) $\times \mathrm{SIC} / \mathrm{BK}$ (nov)
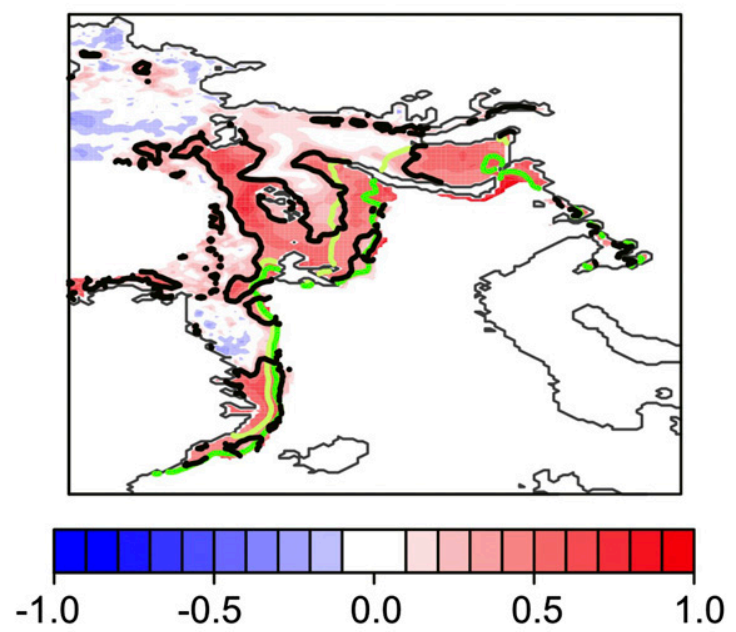

MCA-SIC/BKост x [shf+lhf] (nov)

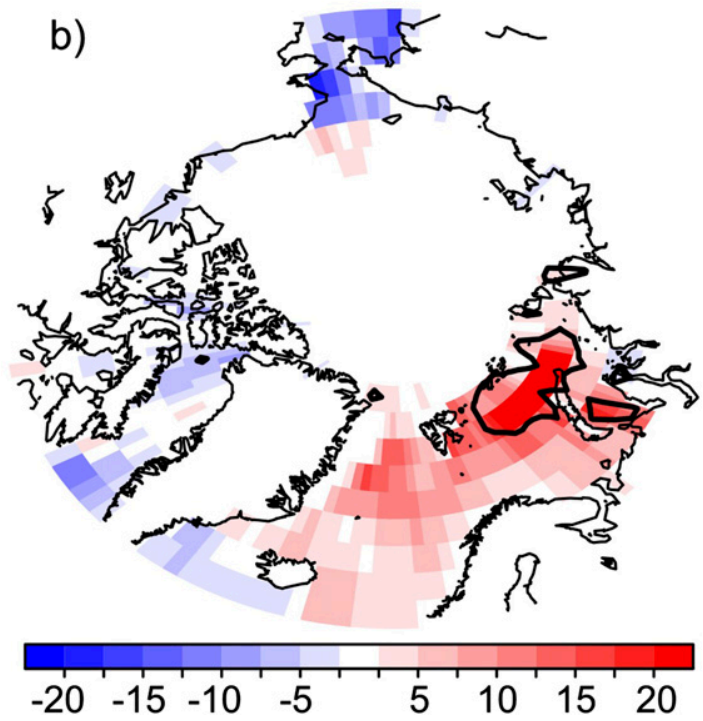

FIG. 14. (a) Gridpoint correlation map of detrended SIC anomalies over the Barents-Kara Seas in October and November; light green (green) contour indicates the climatological sea ice edge in October (November), estimated by the $25 \%$ fraction. (b) As in Fig. 8 b, but with the MCA-SIC/BK ${ }_{\mathrm{OCT}}$ expansion coefficient. Statistically significant areas at $95 \%$ confidence level based on a two-tailed Student's $t$ test are contoured.

et al. 2013), although some efforts are already being carried out (e.g., Batté et al. 2014). In addition, the mechanism identified here supports the notion that dynamical prediction systems will require a proper representation of the stratosphere (Folland et al. 2012), which can be achieved by simulating realistic stratospheric variability and its coupling to the troposphere
(Charlton-Perez et al. 2013) and reducing biases in the climatological polar vortex (Peings et al. 2012).

Acknowledgments. The research leading to these results has received funding from the European Union 7th Framework Programme (FP7 2007-2013), under Grant Agreement 308299 (NACLIM - www.naclim.eu). AdlC is supported by the FP7 project EMBRACE (Grant Agreement 282672) and thanks the Spanish project CGL2012-34997. The authors acknowledge the insightful comments from three anonymous reviewers and thank the editor Dr. John E. Walsh for the help during the review process.

\section{APPENDIX}

\section{Persistence of September Anomalies}

The lagged MCA between September SIC/BK anomalies and the winter Euro-Atlantic atmospheric circulation is not statistically significant enough (see section 3a); hence, the signal-to-noise ratio of this lagged relationship is very low. Accordingly, September SIC/BK does not yield cross-validated skill for winter European SAT or precipitation (not shown) and the cross-validated skill of the NAO index is close to zero (0.09). Yet, the anomalous state of the iceatmosphere interaction in September might have an influence later on the season. This appendix describes the persistence of September anomalies into October and November, the latter being the only one providing climate predictability for the Euro-Atlantic winter through a stratospheric pathway, and the association of surface heat flux anomalies in September with the MCA-SIC/BK expansion coefficients for October and November.

At one-month lag, September SIC anomalies persist over the eastern Arctic, especially in the interior ice pack but also over the northern Barents-Kara Seas (Fig. A1a). September heat flux anomalies persist in this region as well, albeit showing an anticorrelation over the central Kara Sea that reveals a negative feedback (Fig. A1c). Indeed, the negative heat flux anomaly there, preceding MCA-SIC/BK ${ }_{\text {OCT }}$ (Fig. A1e), drives sea ice reduction in October, which then enhances oceanic heat release. At two-month lag, however, neither September SIC (Fig. A1b) nor heat flux (Fig. A1d) anomalies persist over the Barents-Kara Seas. Consistently, no statistically significant heat flux anomalies

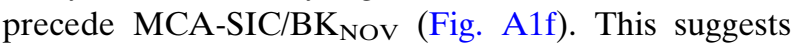
that SIC/BK changes during September could not significantly contribute to the atmospheric teleconnection triggered in November. 
a) $\mathrm{SIC} / \mathrm{BK}($ sep $) \times \mathrm{SIC} / \mathrm{BK}($ oct $)$

b) $\operatorname{SIC} / B K($ sep $) \times \operatorname{SIC} / B K($ nov $)$
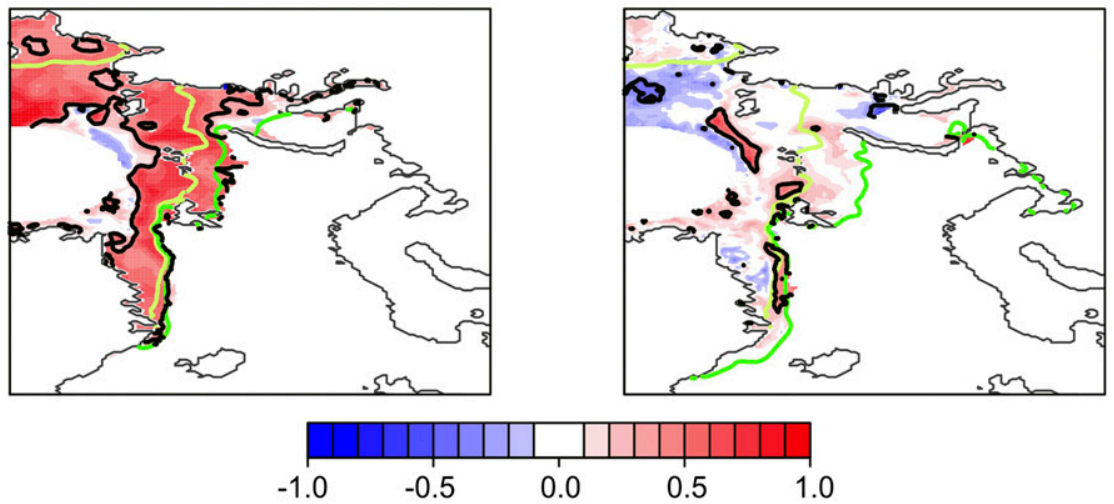

$[\mathrm{shf}+\mathrm{lhf}](\mathrm{sep}) \times[\mathrm{shf}+\mathrm{lhf}]($ oct $) \quad[\mathrm{shf}+\mathrm{lhf}](\mathrm{sep}) \times[\mathrm{shf}+\mathrm{lhf}]($ nov $)$
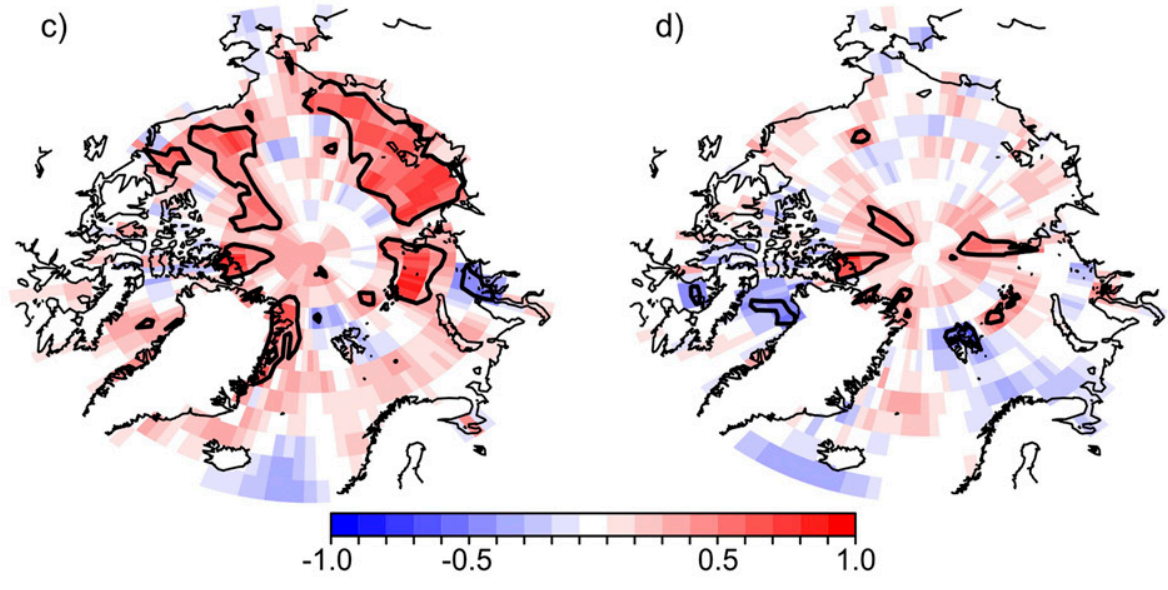

MCA-SIC/BKoct x [shf+lhf] (sep) MCA-SIC/BKNov $x$ [shf+lhf] (sep)

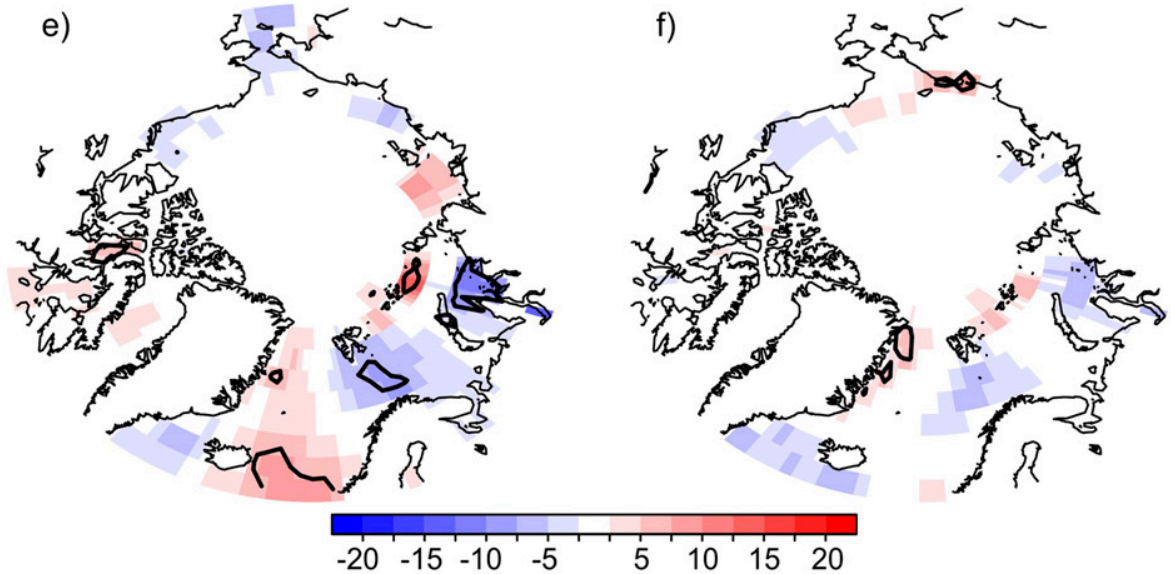

FIG. A1. (top) Gridpoint correlation maps of detrended SIC anomalies over the Barents-Kara Seas in September and (a) October and (b) November; light green (green) contour indicates the climatological sea ice edge in September [October for (a) and November for (b)], estimated by the $25 \%$ fraction. (middle) Gridpoint correlation maps of detrended turbulent heat flux (sensible heat plus latent heat) anomalies in September and (c) October and (d) November. (bottom) Regression maps of detrended turbulent heat flux anomalies ( $\mathrm{W} \mathrm{m}^{-2}$, upward is positive) in September onto the (e) MCA-SIC/BK $\mathrm{OCT}_{\text {}}$ expansion coefficient and (f) MCA-SIC/BK $\mathrm{BK}_{\mathrm{NOV}}$ expansion coefficient. Statistically significant areas at $95 \%$ confidence level based on a two-tailed Student's $t$ test are contoured. 


\section{REFERENCES}

Adler, R. F., and Coauthors, 2003: The Version-2 Global Precipitation Climatology Project (GPCP) monthly precipitation analysis (1979-present). J. Hydrometeor., 4, 1147-1167, doi:10.1175/1525-7541(2003)004<1147:TVGPCP > 2.0.CO;2.

Alexander, M. A., U. S. Bhatt, J. E. Walsh, M. S. Timlin, J. S. Miller, and J. D. Scott, 2004: The atmospheric response to realistic Arctic sea ice anomalies in an AGCM during winter. J. Climate, 17, 890-905, doi:10.1175/1520-0442(2004)017<0890: TARTRA $>2.0 . \mathrm{CO} ; 2$.

Ambaum, M. H. P., and B. J. Hoskins, 2002: The NAO tropospherestratosphere connection. J. Climate, 15, 1969-1978, doi:10.1175/ 1520-0442(2002)015<1969:TNTSC > 2.0.CO;2.

Bader, J., M. D. S. Mesquita, K. I. Hodges, N. Keenlyside, S. Osterhus, and M. Miles, 2011: A review on Northern Hemisphere sea-ice, storminess and the North Atlantic Oscillation: Observations and projected changes. Atmos. Res., 101, 809-834, doi:10.1016/j.atmosres.2011.04.007.

Barnes, E. A., 2013: Revisiting the evidence linking Arctic amplification to extreme weather in midlatitudes. Geophys. Res. Lett., 40, 4728-4733, doi:10.1002/grl.50880.

Batté, L., J. García-Serrano, V. Guemas, M. Asif, I. AndreuBurillo, and F. J. Doblas-Reyes, 2014: Seasonal re-forecasts of the winter NAO with EC-EARTH. Working Group on Numerical Experimentation, Blue Book, S6, 3-4.

Branstator, G., 2002: Circumglobal teleconnections, the jet stream waveguide, and the North Atlantic Oscillation. J. Climate, 15, 18931910, doi:10.1175/1520-0442(2002)015<1893:CTTJSW>2.0.CO;2.

Bretherton, S. B., C. Smith, and J. M. Wallace, 1992: An intercomparison of methods for finding coupled patterns in climate data. J. Climate, 5, 541-560, doi:10.1175/ 1520-0442(1992)005<0541:AIOMFF>2.0.CO;2.

Cassou, C., C. Deser, L. Terray, J. W. Hurrell, and M. Drévillon, 2004: Summer sea surface temperature conditions in the North Atlantic and their impact upon the atmospheric circulation in early winter. J. Climate, 17, 3349-3363, doi:10.1175/ 1520-0442(2004)017<3349:SSSTCI >2.0.CO;2.

Chang, E. K. M., and Y. Fu, 2002: Interdecadal variations in Northern Hemisphere winter storm track intensity. J. Climate, 15, 642-658, doi:10.1175/1520-0442(2002)015<0642: IVINHW $>2.0 . \mathrm{CO} ; 2$.

Charlton, A. J., and L. M. Polvani, 2007: A new look at stratospheric sudden warmings. Part I: Climatology and modeling benchmarks. J. Climate, 20, 449-469, doi:10.1175/JCLI3996.1.

Charlton-Perez, A. J., and Coauthors, 2013: On the lack of stratospheric dynamical variability in low-top versions of the CMIP5 models. J. Geophys. Res. Atmos., 118, 2494-2505, doi:10.1002/jgrd.50125.

Coelho, C. A. S., S. Pezzulli, M. Balmaseda, F. J. Doblas-Reyes, and D. B. Stephenson, 2004: Forecast calibration and combination: A simple Bayesian approach for ENSO. J. Climate, 17, 1504-1516, doi:10.1175/1520-0442(2004)017<1504: FCACAS $>2.0 . \mathrm{CO} ; 2$.

Cohen, J., M. Barlow, P. J. Kushner, and K. Saito, 2007: Stratosphere-troposphere coupling and links with Eurasian land surface variability. J. Climate, 20, 5335-5343, doi:10.1175/ 2007JCLI1725.1.

— treme mid-latitude weather. Nat. Geosci., 7, 627-637, doi:10.1038/ngeo2234.

Comiso, J. C., 2012: Bootstrap sea ice concentrations from Nimbus7 SMMR and DMSP SSM/I-SSMIS. Version 2. National Snow and Ice Data Center, Boulder, CO, digital media. [Available online at http://nsidc.org/data/docs/daac/nsidc0079_bootstrap_ seaice.gd.html.]

Czaja, A., and C. Frankignoul, 2002: Observed impact of Atlantic SST anomalies on the North Atlantic Oscillation. J. Climate, 15, 606-623, doi:10.1175/1520-0442(2002)015<0606: OIOASA $>2.0 . \mathrm{CO} ; 2$.

Dee, D. P., and Coauthors, 2011: The ERA-Interim reanalysis: Configuration and performance of the data assimilation system. Quart. J. Roy. Meteor. Soc., 137, 553-597, doi:10.1002/ qj.828.

Deser, C., J. E. Walsh, and M. S. Timlin, 2000: Arctic sea ice variability in the context of recent atmospheric circulation trends. J. Climate, 13, 617-633, doi:10.1175/1520-0442(2000)013<0617: ASIVIT $>2.0 . \mathrm{CO} ; 2$.

_ , G. Magnusdottir, R. Saravanan, and A. Phillips, 2004: The effects of North Atlantic SST and sea ice anomalies on the winter circulation in CCM3. Part II: Direct and indirect components of the response. J. Climate, 17, 877-889, doi:10.1175/1520-0442(2004)017<0877:TEONAS > 2.0.CO;2.

— R. Tomas, and S. Peng, 2007: The transient atmospheric circulation response to North Atlantic SST and sea ice anomalies. J. Climate, 20, 4751-4767, doi:10.1175/JCLI4278.1.

,,-- M. A. Alexander, and D. Lawrence, 2010: The seasonal atmospheric response to projected Arctic sea ice loss in the late twenty-first century. J. Climate, 23, 333-351, doi:10.1175/ 2009JCLI3053.1.

Doblas-Reyes, F. J., J. García-Serrano, F. Lienert, A. P. Biescas, and L. R. L. Rodrigues, 2013: Seasonal climate predictability and forecasting: Status and prospects. Wiley Interdiscip. Rev.: Climate Change, 4, 245-268, doi:10.1002/wcc.217.

Fletcher, C. G., S. C. Hardiman, P. J. Kushner, and J. Cohen, 2009: The dynamical response to snow cover perturbations in a large ensemble of atmospheric GCM integrations. J. Climate, 22, 1208-1222, doi:10.1175/2008JCLI2505.1.

Folland, C. K., A. A. Scaife, J. Lindesay, and D. B. Stephenson, 2012: How potentially predictable is northern European winter climate a season ahead? Int. J. Climatol., 32, 801-818, doi:10.1002/joc.2314.

Francis, J. A., and S. J. Vavrus, 2012: Evidence linking Arctic amplification to extreme weather in mid-latitudes. Geophys. Res. Lett., 39, L06801, doi:10.1029/2012GL051000.

_-, W. Chan, D. J. Leathers, J. R. Miller, and D. E. Veron, 2009: Winter Northern Hemisphere weather patterns remember summer Arctic sea-ice extent. Geophys. Res. Lett., 36, L07503, doi:10.1029/2009GL037274.

Frankignoul, C., N. Sennéchael, and P. Cauchy, 2014: Observed atmospheric response to cold season sea ice variability in the Arctic. J. Climate, 27, 1243-1254, doi:10.1175/JCLI-D-13-00189.1.

García-Serrano, J., and C. Frankignoul, 2014: High predictability of the winter Euro-Atlantic climate from cryospheric variability. Nature Geosci., 7, E1, doi:10.1038/ngeo2118.

— B. Rodríguez-Fonseca, I. Bladé, P. Zurita-Gotor, and A. de la Cámara, 2011: Rotational atmospheric circulation during North Atlantic-European winter: The influence of ENSO. Climate Dyn., 37, 1727-1743, doi:10.1007/s00382-010-0968-y.

Garfinkel, C. I., D. L. Hartmann, and F. Sassi, 2010: Tropospheric precursors of anomalous Northern Hemisphere stratospheric polar vortices. J. Climate, 23, 3282-3299, doi:10.1175/ 2010JCLI3010.1.

Gerber, E. P., and G. K. Vallis, 2009: On the zonal structure of the North Atlantic Oscillation and annular modes. J. Atmos. Sci., 66, 332-352, doi:10.1175/2008JAS2682.1. 
_- and Coauthors, 2012: Assessing and understanding the impact of stratospheric dynamics and variability on the Earth system. Bull. Amer. Meteor. Soc., 93, 845-859, doi:10.1175/ BAMS-D-11-00145.1.

Germe, A., M. Chevallier, D. Salas y Mélia, E. Sanchez-Gomez, and C. Cassou, 2014: Interannual predictability of Arctic sea ice in a global climate model: Regional contrasts and temporal evolution. Climate Dyn., 43, 2519-2538, doi:10.1007/ s00382-014-2071-2.

Gong, G., D. Entekhabi, and J. Cohen, 2003: Modeled Northern Hemisphere winter climate response to realistic Siberian snow anomalies. J. Climate, 16, 3917-3931, doi:10.1175/ 1520-0442(2003)016<3917:MNHWCR > 2.0.CO;2.

,-- , and -2004 : Orographic constraints on a modeled Siberian snow-tropospheric-stratospheric teleconnection pathway. J. Climate, 17, 1176-1189, doi:10.1175/1520-0442(2004)017<1176: OCOAMS $>2.0 . \mathrm{CO} ; 2$.

Hilmer, M., and T. Jung, 2000: Evidence for a recent change in the link between the North Atlantic Oscillation and Arctic sea ice export. Geophys. Res. Lett., 27, 989-992, doi:10.1029/ 1999GL010944.

Hinssen, Y. B. L., and M. H. P. Ambaum, 2010: Relation between the $100-\mathrm{hPa}$ heat flux and stratospheric potential vorticity. J. Atmos. Sci., 67, 4017-4027, doi:10.1175/2010JAS3569.1.

Honda, M., J. Inoue, and S. Yamane, 2009: Influence of low Arctic sea-ice minima on anomalously cold Eurasian winters. Geophys. Res. Lett., 36, L08707, doi:10.1029/2008GL037079.

Hoskins, B. J., and D. J. Karoly, 1981: The steady linear response of a spherical atmosphere to thermal and orographic forcing. J. Atmos. Sci., 38, 1179-1196, doi:10.1175/ 1520-0469(1981)038<1179:TSLROA > 2.0.CO;2.

- I. N. James, and G. H. White, 1983: The shape, propagation and mean-flow interaction of large-scale weather systems. J. Atmos. Sci., 40, 1595-1612, doi:10.1175/1520-0469(1983)040<1595: TSPAMF $>2.0 . \mathrm{CO} ; 2$.

Hurrell, J. W., and C. Deser, 2009: North Atlantic climate variability: The role of the North Atlantic Oscillation. J. Mar. Syst., 78, 28-41, doi:10.1016/j.jmarsys.2008.11.026.

_- Y. Kushnir, G. Ottersen, and M. Visbeck, 2003: An overview of the North Atlantic Oscillation. The North Atlantic OscillationClimatic Significance and Environmental Impact, Geophys. Monogr., Vol. 134, Amer. Geophys. Union, 1-36.

Inoue, J., M. E. Hori, and K. Takaya, 2012: The role of Barents Sea ice in the wintertime cyclone track and emergence of a warmArctic cold-Siberian anomaly. J. Climate, 25, 2561-2568, doi:10.1175/JCLI-D-11-00449.1.

Johansson, A., 2007: Prediction skill of the NAO and PNA from daily to seasonal time scales. J. Climate, 20, 1957-1975, doi:10.1175/JCLI4072.1.

Jung, T., M. Hilmer, E. Ruprecht, S. Kleppek, S. K. Gulev, and O. Zolina, 2003: Characteristics of the recent eastward shift of interannual NAO variability. J. Climate, 16, 3371-3382, doi:10.1175/1520-0442(2003)016<3371:COTRES > 2.0.CO;2.

_ , F. Vitart, L. Ferranti, and J.-J. Morcrette, 2011: Origin and predictability of the extreme negative NAO winter of 2009/10. Geophys. Res. Lett., 38, L07701, doi:10.1029/ 2011 GL046786.

Karoly, D. J., R. A. Plumb, and M. Ting, 1989: Examples of the horizontal propagation of quasi-stationary waves. J. Atmos. Sci., 46, 2802-2811, doi:10.1175/1520-0469(1989)046<2802: EOTHPO $>2.0 . \mathrm{CO} ; 2$

King, M. P., M. Hell, and N. Keenlyside, 2015: Investigation of the atmospheric mechanisms related to the autumn sea ice and winter circulation link in the Northern Hemisphere. Climate Dyn., doi:10.1007/s00382-015-2639-5.

Kodera, K., and Y. Kuroda, 2000: Tropospheric and stratospheric aspects of the Arctic Oscillation. Geophys. Res. Lett., 27,33493352, doi:10.1029/2000GL012017.

Kolstad, E. W., and A. J. Charlton-Perez, 2011: Observed and simulated precursors of stratospheric polar vortex anomalies in the Northern Hemisphere. Climate Dyn., 37, 1443-1456, doi:10.1007/s00382-010-0919-7.

Kuroda, Y., and K. Kodera, 1999: Role of planetary waves in the stratosphere-troposphere coupled variability in the Northern Hemisphere winter. Geophys. Res. Lett., 26, 2375-2378, doi:10.1029/1999GL900507.

Kushnir, Y., W. A. Robinson, I. Bladé, N. M. J. Hall, S. Peng, and R. Sutton, 2002: Atmospheric GCM response to extratropical SST anomalies: Synthesis and evaluation. J. Climate, 15, 2233-2256, doi:10.1175/1520-0442(2002)015<2233:AGRTES>2.0.CO;2.

Li, F., and H. Wang, 2013: Autumn sea ice cover, winter Northern Hemisphere annular mode, and winter precipitation in Eurasia. J. Climate, 26, 3968-3981, doi:10.1175/JCLI-D-12-00380.1.

Liptak, J., and C. Strong, 2014: The winter atmospheric response to sea ice anomalies in the Barents Sea. J. Climate, 27, 914-924, doi:10.1175/JCLI-D-13-00186.1.

Liu, J., J. A. Curry, H. Wang, M. Song, and R. M. Horton, 2012: Impact of declining Arctic sea ice on winter snowfall. Proc. Natl. Acad. Sci. USA, 109, 4074-4079, doi:10.1073/ pnas. 1114910109 .

Magnusdottir, G., C. Deser, and R. Saravanan, 2004: The effects of North Atlantic SST and sea ice anomalies on the winter circulation in CCM3. Part I: Main features and storm track characteristics of the response. J. Climate, 17, 857-876, doi:10.1175/1520-0442(2004)017<0857:TEONAS > 2.0.CO;2.

Martius, O., L. M. Polvani, and H. C. Davies, 2009: Blocking precursors to stratospheric sudden warming events. Geophys. Res. Lett., 36, L14806, doi:10.1029/2009GL038776.

Mitchell, D. M., L. J. Gray, J. Anstey, M. P. Baldwin, and A. J. Charlton-Perez, 2013: The influence of stratospheric vortex displacements and splits on surface climate. J. Climate, 26, 2668-2682, doi:10.1175/JCLI-D-12-00030.1.

Mori, M., M. Watanabe, H. Shiogama, J. Inoue, and M. Kimoto, 2014: Robust Arctic sea-ice influence on the frequent Eurasian cold winters in the recent past. Nat. Geosci., 7, 869-873, doi:10.1038/ngeo2277.

Newman, P. A., and E. R. Nash, 2000: Quantifying the wave driving of the stratosphere. J. Geophys. Res., 105, 12 485-12497, doi:10.1029/1999JD901191.

Nishii, K., H. Nakamura, and T. Miyasaka, 2009: Modulations in the planetary wave field induced by upward-propagating Rossby wave packets prior to stratospheric sudden warming events: A case-study. Quart. J. Roy. Meteor. Soc., 135, 39-52, doi:10.1002/qj.359.

Peings, Y., D. Saint-Martin, and H. Douville, 2012: A numerical sensitivity study of the influence of Siberian snow on the northern annular mode. J. Climate, 25, 592-607, doi:10.1175/ JCLI-D-11-00038.1.

Petoukhov, V., and V. Semenov, 2010: A link between reduced Barents-Kara sea ice and cold winter extremes over northern continents. J. Geophys. Res., 115, D21111, doi:10.1029/ 2009JD013568.

Polvani, L. M., and D. W. Waugh, 2004: Upward wave activity flux as a precursor to extreme stratospheric events and subsequent anomalous surface weather regimes. J. Climate, 17, 3548-3554, doi:10.1175/1520-0442(2004)017<3548:UWAFAA >2.0.CO;2. 
Rivière, G., and I. Orlanski, 2007: Characteristics of the Atlantic storm-track eddy activity and its relation with the North Atlantic Oscillation. J. Atmos. Sci., 64, 241-266, doi:10.1175/ JAS3850.1.

Rodrigues, L. R. L., J. García-Serrano, and F. J. Doblas-Reyes, 2014: Seasonal forecast quality of the West African monsoon rainfall regimes by multiple forecast systems. J. Geophys. Res. Atmos., 119, 7908-7930, doi:10.1002/2013JD021316.

Scaife, A. A., and Coauthors, 2014: Skillful long-range prediction of European and North American winters. Geophys. Res. Lett., 41, 2514-2519, doi:10.1002/2014GL059637.

Schneider, D. P., E. J. Steig, and J. C. Comiso, 2004: Recent climate variability in Antarctica from satellite-derived temperature data. J. Climate, 17, 1569-1583, doi:10.1175/ 1520-0442(2004)017<1569:RCVIAF >2.0.CO;2.

Screen, J. A., and I. Simmonds, 2013: Exploring links between Arctic amplification and mid-latitude weather. Geophys. Res. Lett., 40, 959-964, doi:10.1002/grl.50174.

,-- C. Deser, and R. Tomas, 2013: The atmospheric response to three decades of observed Arctic sea ice loss. J. Climate, 26, 1230-1248, doi:10.1175/JCLI-D-12-00063.1.

—, C. Deser, I. Simmonds, and R. Tomas, 2014: Atmospheric impacts of Arctic sea-ice loss, 1979-2009: Separating forced change from atmospheric internal variability. Climate Dyn., 43, 333-344, 10.1007/s00382-013-1830-9.

Seierstad, I. A., and J. Bader, 2009: Impact of a projected future Arctic sea ice reduction on extratropical storminess and the NAO. Climate Dyn., 33, 937-943, doi:10.1007/s00382-008-0463-x.

Strong, C., G. Magnusdottir, and H. Stern, 2009: Observed feedback between winter sea ice and the North Atlantic Oscillation. J. Climate, 22, 6021-6032, doi:10.1175/2009JCLI3100.1.

Tang, Q., X. Zhang, X. Yang, and J. A. Francis, 2013: Cold winter extremes in northern continents linked to Arctic sea ice loss. Environ. Res. Lett., 8, 014036, doi:10.1088/ 1748-9326/8/1/014036.

Thompson, D. W. J., S. Lee, and M. P. Baldwin, 2003: Atmospheric processes governing the Northern Hemisphere annular mode/North Atlantic Oscillation. The North Atlantic Oscillation-Climatic Significance and Environmental Impact, Geophys. Monogr., Vol. 134, Amer. Geophys. Union, 81-112.

Tomassini, L., E. P. Gerber, M. P. Baldwin, F. Bunzel, and M. Giorgetta, 2012: The role of stratosphere-troposphere coupling in the occurrence of extreme winter cold spells over northern Europe. J. Adv. Model. Earth Syst., 4, M00A03, doi:10.1029/2012MS000177.

Trenberth, K. E., 1986: An assessment of the impact of transient eddies on the zonal flow during a blocking episode using localized Eliassen-Palm flux diagnostics. J. Atmos. Sci., 43, 2070-2087, doi:10.1175/1520-0469(1986)043<2070:AAOTIO>2.0.CO;2.

Vallis, G. K., and E. P. Gerber, 2008: Local and hemispheric dynamics of the North Atlantic Oscillation, annular patterns and the zonal index. Dyn. Atmos. Oceans, 44, 184-212, doi:10.1016/j.dynatmoce.2007.04.003.

,-- , P. J. Kushner, and B. A. Cash, 2004: A mechanism and simple dynamical model of the North Atlantic Oscillation and annular modes. J. Atmos. Sci., 61, 264-280, doi:10.1175/ 1520-0469(2004)061<0264:AMASDM>2.0.CO;2.

Vihma, T., 2014: Effects of Arctic sea ice decline on weather and climate: A review. Surv. Geophys., 35, 1175-1214, doi:10.1007/ s10712-014-9284-0.

Wallace, J. M., G. H. Lim, and M. L. Blackmon, 1988: Relationship between cyclone tracks, anticyclone tracks and baroclinic waveguides. J. Atmos. Sci., 45, 439-462, doi:10.1175/ 1520-0469(1988)045<0439:RBCTAT>2.0.CO;2.

—, C. Smith, and C. S. Bretherton, 1992: Singular value decomposition of winter sea surface temperature and $500-\mathrm{mb}$ height anomalies. J. Climate, 5, 561-576, doi:10.1175/ 1520-0442(1992)005<0561:SVDOWS >2.0.CO;2.

Walsh, J. E., 2014: Intensified warming of the Arctic: Causes and impacts on middle latitudes. Global Planet. Change, 117, 52 63, doi:10.1016/j.gloplacha.2014.03.003.

_ and associated fluctuations in Arctic sea ice extent. J. Geophys. Res., 84, 6915-6928, doi:10.1029/JC084iC11p06915.

Watanabe, M., 2009: Self-limiting feedback between baroclinic waves and a NAO-like sheared zonal flow. Geophys. Res. Lett., 36, L08803, doi:10.1029/2009GL037176.

Woollings, T., B. J. Hoskins, M. Blackburn, and P. Berrisford, 2008: A new Rossby wave-breaking interpretation of the North Atlantic Oscillation. J. Atmos. Sci., 65, 609-626, doi:10.1175/ 2007JAS2347.1.

Wu, Q., and X. Zhang, 2010: Observed forcing-feedback process between Northern Hemisphere atmospheric circulation and Arctic sea ice coverage. J. Geophys. Res., 115, D14119, doi:10.1029/2009JD013574 